\title{
Youth, Media and Moral Panic: A Sociological Investigation into Dalton McGuinty's "Rethink" of the 2010 Health and Physical Education Curriculum
}

\author{
by \\ Patricia Lee Hoyland \\ B.A with Honours in Sociology, St. Francis Xavier University, \\ 2009
}

A thesis submitted to the Faculty of Graduate and Postdoctoral Affairs in partial fulfillment of the requirements for the degree of

Master of Arts

in

Sociology

Carleton University

Ottawa, Ontario

(C) 2012, Patricia Lee Hoyland 
Library and Archives

Canada

Published Heritage

Branch

395 Wellington Street

Ottawa ON K1A ON4

Canada
Bibliothèque et

Archives Canada

Direction du

Patrimoine de l'édition

395 , rue Wellington

Ottawa ON K1A ON4

Canada
Your file Votre référence

ISBN: $978-0-494-93595-8$

Our file Notre référence

ISBN: $978-0-494-93595-8$
NOTICE:

The author has granted a nonexclusive license allowing Library and Archives Canada to reproduce, publish, archive, preserve, conserve, communicate to the public by telecommunication or on the Internet, loan, distrbute and sell theses worldwide, for commercial or noncommercial purposes, in microform, paper, electronic and/or any other formats.

The author retains copyright ownership and moral rights in this thesis. Neither the thesis nor substantial extracts from it may be printed or otherwise reproduced without the author's permission.
AVIS:

L'auteur a accordé une licence non exclusive permettant à la Bibliothèque et Archives Canada de reproduire, publier, archiver, sauvegarder, conserver, transmettre au public par télécommunication ou par l'Internet, prêter, distribuer et vendre des thèses partout dans le monde, à des fins commerciales ou autres, sur support microforme, papier, électronique et/ou autres formats.

L'auteur conserve la propriété du droit d'auteur et des droits moraux qui protege cette thèse. $\mathrm{Ni}$ la thèse ni des extraits substantiels de celle-ci ne doivent être imprimés ou autrement reproduits sans son autorisation.
In compliance with the Canadian Privacy Act some supporting forms may have been removed from this thesis.

While these forms may be included in the document page count, their removal does not represent any loss of content from the thesis.
Conformément à la loi canadienne sur la protection de la vie privée, quelques formulaires secondaires ont été enlevés de cette thèse.

Bien que ces formulaires aient inclus dans la pagination, il n'y aura aucun contenu manquant. 


\begin{abstract}
Although it is widely accepted that late modern societies are becoming more liberal and open about issues relating to sex and sexuality, there remain a number of associated anxieties and moral panics surrounding the ways in which certain sex acts and relations are socially ordered. Given that panics around the regulation of youth sexuality are especially potent, sex education in schools has emerged as one way for youth sexuality to be managed in Western culture. This thesis will examine the connections between youth and sexuality, by exploring media constructions of the anxieties provoked by new sex education curriculum that was to be implemented in Ontario schools in 2010. Although the proposed curriculum had been thoroughly researched and consulted, it was never put into place in large part due to the media orchestrated panic surrounding its content and objectives. Drawing on Michel Foucault and Stanley Cohen, this thesis maps the development of this media produced moral panic and evidences how discourses of corruption and danger were mobilized to retract the curriculum.
\end{abstract}




\section{Acknowledgements}

I would like to take this time to ensure that everyone who has motivated and helped me through this process understands how much I appreciate their support. In particular, my thesis committee, Dr. Lara Karaian and Dr. Erin Connell for all their enlightening comments, constructive critiques, and their abilities to encourage me to continue with the process.

I would also like to thank the classmates and dear friends I have met at Carleton for the intellectual stimulation and critical dialogue that they have provided. In particular, Ryan Boyd, Steve Richardson, Justine Chapman, Rebecca Hosker, Sesadri Bell, Patrick Dwyer, JP Crete and Kayla Turpin. I could not have gotten through the last two years without the 'Mike's Place' group therapy sessions!

I must also express gratitude to both Aaron Doyle and Paula Whissell, two of the kindest and most helpful people I have ever had the pleasure of meeting. You were always there to answer questions and guide my post-graduate path, and your unparalleled kindness did not go unnoticed.

Lastly, I have to offer my deepest gratitude to Dr. Riley Olstead. If not for Riley, I would never have applied to grad school, ended up at Carleton or likely finished my Masters degree. Riley, you have been a beacon of support for the last four years in anything and everything I have attempted, and are the best editor a girl could ask for. You have been a fantastic teacher, an inspiring mentor, and a great friend. I thank you for everything you've done for me. 


\section{Table of Contents}

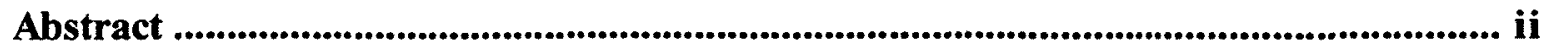

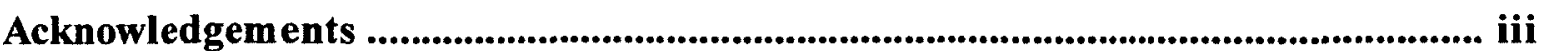

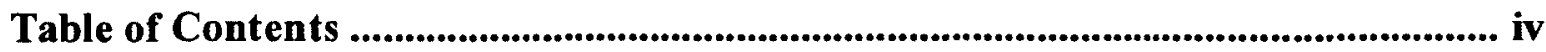

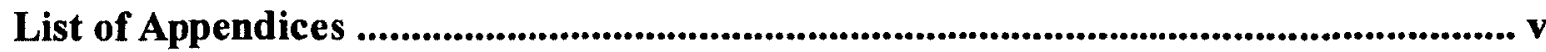

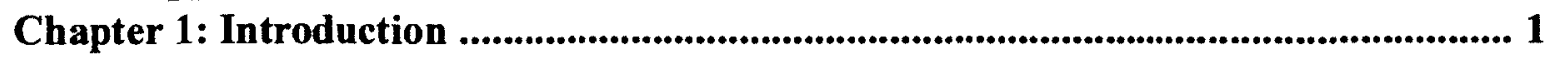

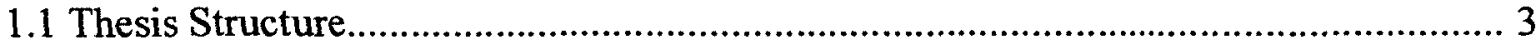

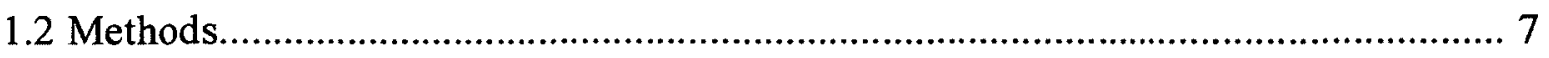

1.3 Concluding Remarks................................................................................. 10

Chapter 2: Assessing the Literature .................................................................. 12

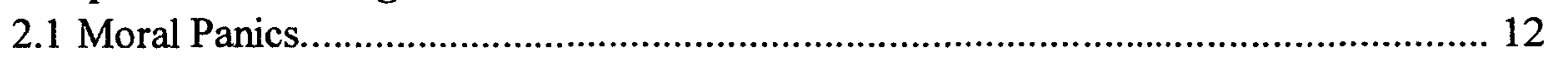

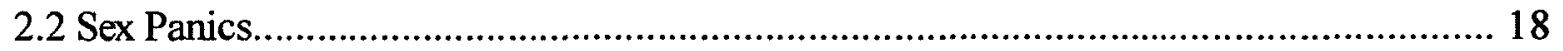

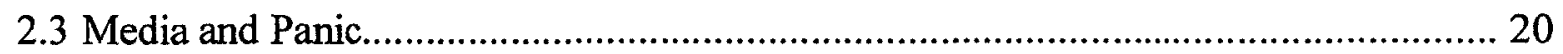

2.4 Media, Sexuality and Youth........................................................................... 25

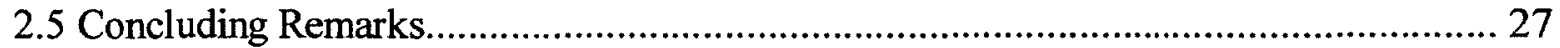

Chapter 3: Theoretical Framework ...................................................................... 29

3.1 The Social Construction of Sex and the Emergent of the Sexual Deviant.................. 30

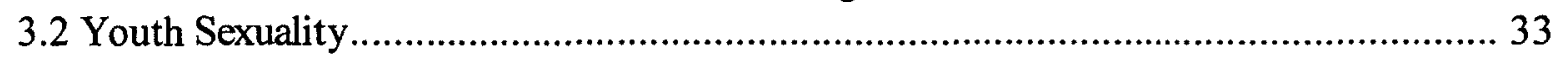

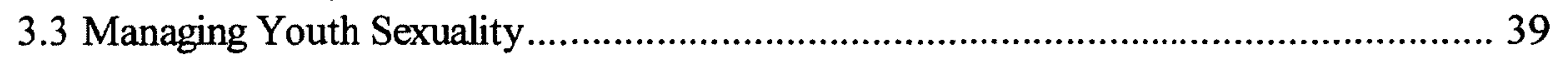

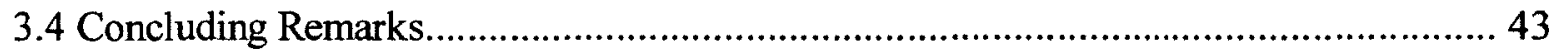

Chapter 4: Health and Physical Education As a Moral Panic ............................... 45

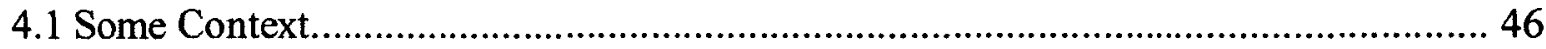

4.2 Exaggeration and Distortion.................................................................... 51

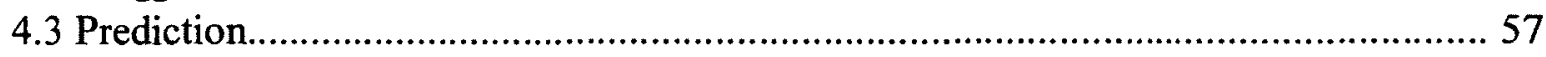

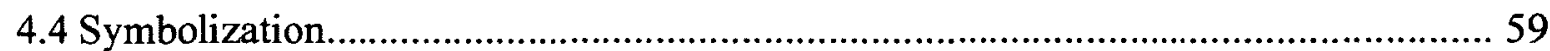

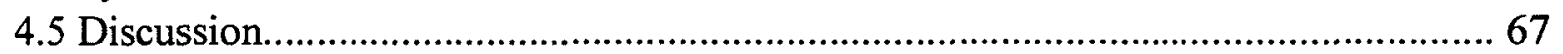

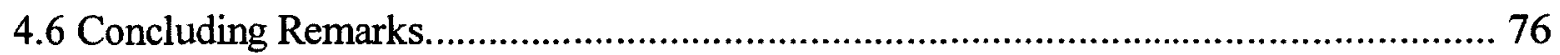

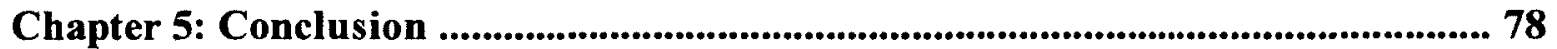

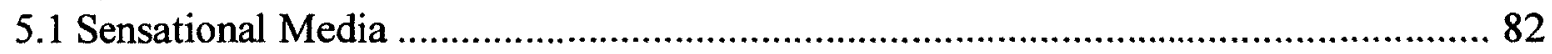

5.2 Where Do We Go From Here?.................................................................... 84

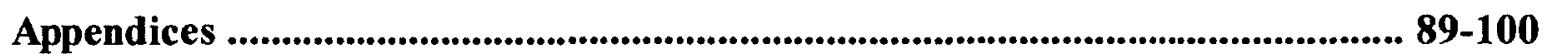

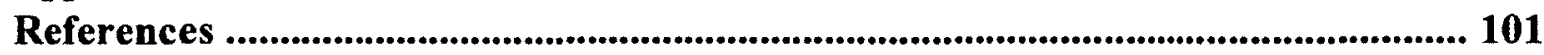




\section{List of Appendices}

Appendix A- Healthy Living Summary: Key Topics. Proposed Health and Physical Education Curriculum, Grades 1-8.

Appendix B- "Birds and Bees to be taught from Grade 3". Initial newspaper article from The Hamilton Spectator

Appendix C- "Mr. McGuinty, Withdraw Sex Ed for 8 year-olds" - Press release by Charles McVety

Appendix D- Complete list of "Teacher Prompts" from 2010 Proposed Health and Physical Education Curriculum- Healthy Livings Strands, Grades 1-8. 


\section{Chapter 1- Introduction}

In 2010 the Ontario Ministry of Education released a Health and Physical Education (HPE) curriculum, which included a section on sex education. It included discussions around sexual orientation/gender identity, healthy relationships, the physical development associated with puberty and STI (sexually transmitted infections) and pregnancy prevention (see Appendix A for curriculum summary). It was to be implemented in all publicly funded schools (both secular and Catholic) beginning in grade one and continuing to the end of grade eight ${ }^{1}$. The curriculum was made public and placed on the Ministry's website, and was met with little opposition. Four months passed without incident, until Charles McVety, the leader of a conservative religious organization, the Canadian Family Action Coalition, issued a press release denouncing the curriculum and calling for Premier McGuinty to retract the sex education portions. The press release was met with a fury of media response (in the form of editorials, letters to the editor and official responses from educators) and McGuinty eventually retracted the sex education components.

This thesis explores how concerned parents, teachers and citizens effectively shut down the HPE curriculum by aligning its content with popular discourses associating sex with the corruptibility of youth and broad social and moral decline. Drawing on Stanley Cohen's (1972) conceptualization of moral panics I employ a discourse analysis to

\footnotetext{
${ }^{1}$ The Ministry of Education has separate secondary and elementary HPE curriculums and while the two curriculums are designed using a continuum of learning they are physically two separate documents. The revised secondary curriculum is still in approvals at this time but it is hoped that the course description will be ready for release this fall and implementation could then happen in 2013.Therefore this thesis is based exclusively on the primary school (grade 1-8) curriculum that was released in 2010.
} 
examine popular media coverage of the HPE debates in order to demonstrate how the media was used to organize a moral panic around this issue. In the chapters that follow, I show how this was accomplished, in large part via the mobilization of powerful discourses surrounding youth sexuality, particular to social modernity. In particular, I illuminate how the social construction of youth sexuality was used as a regulatory mechanism to limit how people could respond to the contested moral and social uncertainties that sex education raises.

My concern with the media stems from an acknowledgement of both the pervasiveness and significant effect that popular media has on public perception. For instance, it is clear from studying the data gathered for this research, that the media can play on the concerns of the public and can create social problems quite suddenly and dramatically (March and Melville 2011). The mass media is a significant force in defining and shaping social problems and has devoted a great deal of time and space to deviance, including, but not limited to, youth, sex and perversity (Philo 1996). With this in mind, it is not surprising that the media has been described as an agent of social control, in which popular images and the way that information is presented by media can shape our understanding of certain behaviours (Critcher 2006:34). Consequently, the questions raised in this thesis are borne out of the understanding that media representations are not simply representations, but have the power to reinforce feelings of anxiety and trepidation over a situation (Jenkins 1998:54) and decrease critical resistance to certain topics. In fact, in some cases the nature of media depictions has, in combination with particular social situations, produced a moral panic. 
My interest in the pages that follow is to assess the HPE panic. The HPE debates are especially suitable for an analysis of media orchestrated panics, precisely because the "discussion" about the curriculum was articulated almost exclusively through media, and particularly in letters to the editor and opinion articles published in newspapers and on newspaper websites. It is my belief that an understanding of how and why this moral panic emerged will shift our focus on sex education opposition and serve as a starting point for the inevitable release of a new curriculum in the future. At the present time, Ontario youth are receiving sex education that was created in 1998, and does not include many of the contemporary realities that permeate modernity ${ }^{2}$, such as an increasing move away from nuclear families and a lower number of people affiliated with organized religion. If the Ministry of Education is sincere in its mandate to update all existing curriculums to make them applicable in the $21^{\text {st }}$ century, then the HPE curriculum will be reviewed and revised again in the near future. It is my hope that a thorough understanding of the techniques and strategies that were mobilized by the opposition in 2010 will lead to a more successful release and implementation of future HPE curriculums.

\subsection{Thesis Structure}

The theory of moral panics occupies a pivotal place in the sociology of collective behaviour and social deviance. British sociologist Jock Young pioneered the application of the term in 1971, to refer to public concern over apparent increases in drug abuse in Britain. He suggested not only that a moral panic ensued, but also that the panic itself led

\footnotetext{
${ }^{2}$ I use Chris Barker's (2005) definition of this term throughout this thesis to refer to the period "marked by the move away from feudalism toward capitalism, industrialization, secularization, rationalization, the nation-state and its constituent institutions and various forms of surveillance" (444).
} 
to increased drug-related arrests, thereby amplifying the deviance under examination (Young 1971). Stanley Cohen (1972) furthered this model, with his analysis of youth disturbances in Clacton, England between the Mods and the Rockers in the 1960's. Collectively, Cohen described moral panics as the escalating effects created by the mobilization of media, public opinion and various agents of social control around a perceived social problem. Put another way:

A condition, episode or group of persons emerges to become defined as a threat to societal values and interests; its nature is presented in a stylized and stereotypical fashion by the mass media; the moral barricades are manned by editors, bishops, politicians and other right-thinking people; socially accredited experts pronounce their diagnoses and solutions; ways of coping are evolved (or more often) resorted to; the condition then disappears, submerges or deteriorates and becomes visible (9).

In Chapter Two of this thesis, I focus on the criteria and definition of moral panic, using Stanley Cohen's original assessment of the Mods and Rockers as an empirical example. I reference Good and Ben Yehuda's (1994) criteria for knowing when a moral panic has gripped a certain society and examine the literature that explores the relationship between moral panics, sex panics and particular social and moral climates. Further, I develop a theory of media and critically examine its role in the perpetuation and facilitation of moral/sex panics.

In Chapter Three I draw on the work of Michel Foucualt $(1972,1978)$ to develop an understanding of the specialness of sex and sexuality in understanding human bodies and regulating social actions, and use the work of Postman (1994), Hall (1904) and Adams (1997) to explore the discursive construction/regulation of youth. Using Foucault's critique of the repressive hypothesis and the discursive explosion of sex and sexuality, I show how -through the rise of sexology and scientific discourses- 
monogamous, heterosexual encounters is the dominant model of sexuality in Western culture. I indicate how sexuality has been constructed and subject to social, political and ideological influences and how sex and sexuality have become central to our definitions of normality (Weeks 1986:26).

To elaborate on some of the social considerations around the emergence of the HPE panic, I then explore the historical emergence of the social category of "youth" to understand the cultural anxieties that exist around the transition from childhood to adulthood and the sexual connotations that this transition embodies. Using Hall's (1904) recapitulation theory, I also illuminate an important link between youth and notions of "cultural betterment", and suggest that this association had profound effects upon the HPE debates, inasmuch as they were an instance of more broadly felt concerns about the survival of Western society. In addition, I draw on the works of theorists and scholars, such as Gayle Rubin (1985) to couch the HPE debates within an understanding of the ways that youth sexuality is regulated and controlled. Rubin specifically draws attention to the fact that society continually refuses to recognize the sexuality of the young and instead of trying "to provide for it in a caring and responsible manner, our culture ... punishes erotic interest and activity [for] anyone under the local age of consent" (158). Here I will explore the current tension that exists in trying to regulate the sexuality of youth amid a culture of ubiquitous sexualization and eroticization of young people within mainstream media.

Chapters Two and Three provide both the conceptual tools and theoretical underpinnings that are essential to my analysis. In Chapter Four I draw links between the unique and anxiety ridden categories of youth and sexuality and align my analysis with 
Cohen (1972) and Goode \& Ben-Yehuda's (1994) conceptualization of (media orchestrated) moral panics. Here, I use the Ontario HPE curriculum debates as a particular instance of a media orchestrated sex panic and illuminate the specific "hot spot" issues that were utilized by opposition to retract the curriculum. In Chapter Five, I make reference to these topics alongside more contemporary reasons for the panic existing, such as the ubiquitous sexualization of children in mainstream media and an increasing desperatism by print media to print provocative and sensational stories to attract readers.

Until recently, there was a widely held assumption that it was inappropriate to discuss sexuality with children and youth, as such a discussion would corrupt youthful innocence and predispose some children to immoral behavior (McKay 1998:27). However "the question of whether sexuality should be hidden from youth is now more or less moot as various forms of media continually expose youth to sexual oriented imagery" (28) and one of the ways to combat the sexualized images that children and youth are bombarded with on a daily basis, has been the implementation of sex education in schools.

In their study of adolescent sexual behavior, Zabin and Hayward (1993) noted that, "young men and women adopt sexual behaviors at a time that is influenced by hormonal developments but they [also] follow a script that is largely determined by social expectations" (41). Therefore there is reason to believe that although youth sexuality is guided partly by an innate biological drive, the sexual socialization of youth is largely affected by social forces defining "normal" and "abnormal" behaviors. But as cultural diversity in sexual norms and values becomes more and more of a reality in Western 
culture, a unified set of rules and guidelines in relation to youth sexuality becomes much harder to define.

There is considerable evidence that school based sexual education programs influence youth's sexual knowledge and behaviours (Kirby 1992; Frost and Forrest 1995; Mauldon and Luker 1996), so it is no surprise that with the plethora of competing opinions, values and perspectives, the material presented in Canadian classrooms around sex and sexuality is a topic of polarized debate. By exploring the construction of the HPE curriculum debate and breaking down the linguistic and semiotic devices that were disseminated through print media to justify retraction of the curriculum, this thesis aims to illuminate the cultural discomforts with youth and their access to sexual knowledge. Looking closely at the HPE curriculum, I will provide a nuanced understanding of the naturalized meanings that "youth sex" has come to embody and show how these meanings are deployed as a form of social regulation and control.

\section{2-Methods}

Drawing on the work of Foucault $(1978,1972)$, the methodology I employ in this thesis is that of an intensive discourse analysis of the myriad of techniques used to produce youth as vulnerable and sexuality as corrupted by the proposed curriculum. Useful to my analysis is Foucault's (1972) view that asserts that discourse serves the purpose of a social system, not by imposing silence, but through a proliferation of talk that alters the way we think and function as a society. My concern is to examine the talk that emerged around the sex curriculum in order to make connections between the HPE panic, and the dominant cultural views around sex and youth. Discourse analysis implies a dialectical 
relationship between a particular discursive event and the situations, institutions and social structures that frame it (Meyer and Wodak 2009). Discourse then, is both socially constitutive as well as socially conditioned.

However it is worth bearing in mind that discourse is most often considered a "natural" product-something akin to common sense. However, because power is entwined with language, in the sense that language indexes and expresses power, and is involved where there is contention over and a challenge to power, by analyzing naturalized discourses, researchers can illuminate certain constitutive elements and characteristics of society that are otherwise taken-for-granted as natural or inevitable (Meyer and Wodak 2009). Critical discourse analysis (CDA), in particular, is interested in the structural relationships of dominance, discrimination, power, and control as manifested in language; CDA connects language and speech to social structure.

For the purpose of my project, I will engage a combined method of Foucauldian discourse analysis and critical discourse analysis. In this way, I bring to the surface the ways in which dominating discourses around youth sexuality inform a set of practises that allow for the specification and classification of certain (youth) sexualities. By examining who the opponents of the curriculum were, where these individuals and groups were situated, what the sources of contestation were and when the opposition emerged, I will gain insight into the precarious relationship between youth and sex and the potent anxiety that has emerged in western culture around these two constructs. Collectively these themes help me answer how and why opposition was constructed to the HPE curriculum in April 2010 and how the media was used as a platform to perpetuate the panic. In doing so, I illuminate the ways in which youth sexuality is disclosed as a 
truth discourse and how particular understandings of protection/regulation, innocence, vulnerability and potential danger have consolidated to produce the "sexual youth".

The content of my analysis includes relevant newspaper articles that I have found using the terms "sex education" and "Ontario" on both Lexis/Nexis and Factivia search engines. I have restricted my search to print media or online articles printed on newspaper websites, and used only articles that were published between April and May 2010, as everything I uncovered after this date about the HPE curriculum, only mentioned it in passing ${ }^{3}$. Although there was a large amount of online material (in the form of blogs, resistance through social networking sites, message boards and chat rooms) surrounding the HPE curriculum, I chose to examine newspapers for two reasons. The first, being the sheer ubiquity of the Internet and personal concern that online sources are less regulated and highly anonymous. This makes it extremely difficult to navigate the oppositional terrain and determine "who" the opposition really was. The second reason I chose to use print media is based on the user demographic of such a media. Unlike users of cyber technologies, studies in print media have routinely shown higher levels of newspaper article reading among older generations, who are more engaged in civic participation (see Shah, McLeod and Yoon 2001 for further reading). Therefore, I believe that examining opposition articulated through newspapers, offers a more active opposition than blogs and other online sources would.

${ }^{3}$ Around the same time as the HPE debates, Dalton McGuinty was also fighting a battle with pharmacists over prescription drug prices and numerous opponents of the $13 \%$ harmonized sales tax that was being implemented in the province two months later. The HPE "rethink" was only mentioned alongside these controversial government decisions within discussions of McGuinty's leadership and policy longevity. 
My search was open to all Canadian media, but the majority of data came from Ontario-based newspapers, such as the Guelph Mercury, Ottawa Citizen, Toronto Star, Cambridge Reporter, Hamilton Spectator and Windsor Star. My analysis examines editorial articles, as well as letters to the editor. Unlike editorial articles, letters to the editor are edited more heavily for space considerations, than content. For this reason, letters to the editor offer a valuable view of the raw semantic construction of opposition to the curriculum. My search resulted in 406 articles, all of which I reviewed and analyzed. I examined the obvious content of the articles and letters, but also looked at aspects such as the actors involved in the article or quote. For example, was the opponent a parent, or a veteran teacher or community leader? Were youth given a voice within media representations? I also looked at the vocabulary and style used, the form of argumentation and rhetoric, and the linguistic and semiotic devices that were used. The selected key quotes and excerpts that I present in chapter four were chosen because of both their frequency throughout the data as well as their extensive representations of HPE opposition.

\section{$\underline{1.3-\text { Concluding Remarks }}$}

According to the moral panic literature, panics only occur in societies where the collective conscious tends to be weak. They serve the purpose of pointing out where moral boundaries need strengthening, and the focus of the panic becomes a symbolic surface in which anxieties and fears are exorcised. With this context in mind, the panic over the HPE curriculum was not simply about sex education. Indeed, there are larger, foundational worries surrounding the connection between youth and sex. Using sex 
education as a particular instance, my thesis offers an examination of a sex panic to interrogate the relationship between contemporary mass media and our own social anxieties and fears about the unresolved tensions at the core of social life and living. By examining the media's role in the creation of youth as a ritualized moral boundary, this thesis is an opportunity to raise questions about the significance and consequence of assigning moral boundaries and how they serve to strengthen and regulate moral and institutionalized uncertainties. 


\section{Chapter 2- Assessing the Literature}

\section{1-Moral Panics}

The Mods and Rockers

On Halloween Day, 1964 in the small seaside village of Clacton, England, a young bartender refused service to several young people. A small fight broke out, resulting in approximately five hundred pounds worth of damage; a few beach huts were destroyed and some windows broken. The police arrested nearly one hundred adolescents for their role in the property damage (Goode and Ben-Yehuda 1994:21-23). Despite the ordinariness of these events, what occurred in the days following was anything but. News media ran stories about the two core teenage groups reportedly involved (the Mods and Rockers), couched within stories of "youth violence", "mob mentality" and the "dangerousness of adolescents" to innocent vacationers of the resort community of Clacton. What was otherwise a mundane scuffle became the stuff of sensation with stories appearing in nearly every national newspaper and televised news show. Not only was the "orgy of sensationalistic news" (22) apparent in England, but also Canada, the United States, Australia and South Africa. In fact, the topic of youth fights and vandalism continued to be a theme in popular British press for nearly three years after the incident, all of which was couched in the same inflated, sensation typical of the Clacton reports $(22-25)$

Stanley Cohen (1972) took particular interest in the disproportionate and sensationalized reaction to the activities of the rebellious youth activities that occurred in Clacton; coming to determine that the media "frenzy" reflected a form of moral panic. He used the term "as a means of characterizing the reactions of the media, the public, and 
agents of social control to youth disturbances" (24). He later expanded his definition to refer to "an episode, condition, person or group of persons that have in recent times, been defined as a threat to societal values and interests" (9). Cohen's work on the Mods and Rockers was one of the first empirical manifestations of this concept; however, it has since been used by many theorists, scholars and academics to explore a variety of social problems.

In this chapter, I will use Cohen's theory and the literature on moral panics in order to provide a conceptual framework for my own project. This section will serve as both a review of the literature on moral panics, and will provide a conceptual tool for a moral panic analysis. Given that much of the 2010 HPE debate played out through mainstream print media this chapter goes beyond clarifying the conceptual foundation of the mass media in facilitating a specific panic, and examines the literature that links youth, sex and media.

\section{What is a moral panic?}

"During a moral panic the behavior of some members of a society is thought to be so problematic to others, the evil they do, or are thought to do, is felt to be so wounding to the substance and the fabric of the body social, that serious steps must be taken to control the behavior, punish the perpetrator, and repair the damage" (Goode and Ben-Yehuda 1994:31).

A moral panic occurs when a group or category of people is said to engage in immoral behaviour that, if unstopped, has the potential for serious social consequences. This causes a "fever" of emotions and reactions among members of society at large, presumably because they feel threatened. Feelings of threat are often reinforced by the stylized, inaccurate and stereotypical reporting of the mass media. As Cohen (1972) 
explains, the term moral panic "is a means of characterizing the reactions of the media, the public, and agents of social control to [the immoral behavior]" (9). The "immoral" group is identified as "the enemy" or contemporary "folk devil". A folk devil is a particular group towards which society directs its self-righteous anger and animosity. Folk devils are personifications of evil; they become stripped of all favourable characteristics, and become demonized in a particular society. Moral panics by their very nature "identify, denounce, and attempt to root out folk devils" (Goode and Ben-Yehuda 1994:29).

Moral panics are characterized by a feeling held by a significant number of members of a society, that the particular behaviour of a certain group endangers the moral fabric of society. Such thinking legitimizes and motivates the strengthening of the social control apparatuses of society. These may include new and tighter legislation, harsher punishments, increased ostracism, fortified police enforcement as well as the implementation of more prisons. Although not all people will agree that punitive measures are the answer, moral panics are always accompanied by the debate about appropriate social and/or legal controls (Goode and Ben-Yehuda 1994).

For Goode and Ben-Yehuda (1994), moral panics are characterized by five elements: concern, hostility, consensus, disproportionality and volatility. Together, these serve as indicators for knowing how and when a moral panic is organizing around a given situation.

To be a moral panic, there must first be a heightened level of concern over the behaviours or actions of a particular group in society, which manifests in a tangible way. This may include heightened media attention, social movement activity and/or proposed 
legislation. Secondly, with the concern about, and identification of a particular "problematic" group comes a heightened level of hostility towards members of that group. Their behaviour is seen as harmful to a certain segment of society, but more, to the fundamental values of the society in which the panic occurs. As a certain group becomes constituted as a threat to society, a clear distinction develops between constructions of an "us" -the good respectable citizen- and a "them", deviants, outsiders and criminals (34). Thirdly, there also must be substantial and widespread agreement among members of society about the threat that the problem group poses. Although regional variations may exist, moral panics erupt when a general consensus emerges among people. Fourthly, there must be a disproportional negative reaction to the problem group. As was the case with Cohen's (1972) Mods and Rockers, public concern must exceed what is a reasonable assessment of real damage or risk. The final characteristic of a moral panic is volatility. Often, panics erupt quite suddenly, yet almost as suddenly, they may subside. The degree of hostility that is generated during a panic is commonly temporary, thus for Cohen, moral panics are extreme collective ruptures that are temporally limited (39).

According to Cohen, an additional consideration for determining whether a moral panic is occurring is the delineation of a scapegoat or folk devil to act as an identifiable object onto which social fears and anxieties may be projected. As the personification of evil, the folk devil is conceived in such a way that it can be instantly recognized as an "unambiguously unfavorable symbol" (41), stripped of any positive characteristics and endowed with pejorative evaluations. This conception goes beyond the psychological concept of the stereotype; rather, it is a shorthanded way of referring to social relationships. These relationships are socially produced and contain a large element of 
reality, which become naturalized into "common-sense" notions through a complex chain of social interactions involving claims makers, moral guardians and the media. These interactions occur within a context of socio-political change and a climate of cultural ambiguity. What this signifies for Cohen is that, although moral panics center on a particular folk devil, the locus of the panic is not the object of its symbolic resonances. Rather, folk devils serve as the conceptual expression of deeper anxieties, perceived of as "a problem" only in and through social definition and construction (Hier 2002).

\section{When and why do moral panics erupt?}

Most moral panics do not emerge in reaction to tangible physical threats to members of a society (Critcher 2006:139). Rather, as Cohen and Young (1973) describe, moral panics are the escalating effects created by an orchestrated mobilization on the part of the media, public opinion, and various agents of social control. The social construction of what counts as a social problem is culturally relative and differs from one society, group or subculture to another. In order to determine how and why certain behaviours, ideas or people are considered to be deviant, one must look at how a particular society defines, judges and values behaviour in a specific context (Jenkins 1998; Plummer 1975; Thompson 1998; Weeks 1986). Condemnation of certain practices as deviant is not inevitable; it grows out of particular social characteristics of society. Thus, public concern can emerge to some degree, independently of the objective threat of the behaviour (Goode and Ben-Yehuda 1994:74).

Moral panics are tangible evidence of troubling behaviors that society perceives as beyond control and that therefore threaten the social body (Critcher 2006:7). However 
the relationships between moral panics and social changes are complex and involve underlying chronic anxiety about the state of moral life and the resilience and integrity of broad social bonds. For instance, Cohen (1972) recognized that the fear felt about the Mods and Rockers could not have emerged without the underlying social and political crisis to the panic social context. He borrows Erickson's (1966) term "boundary crisis"- a period in which a group's social anxiety about themselves becomes manifested in confrontation between a group considered to be deviant, and the agents of social control of a particular society.

Goode and Ben-Yehuda (1994) argue that boundary crises emerge in large, pluralistic, agrarian, industrial societies where the collective conscience tends to be weak resulting in challenges to the moral universe from competing moral centers (76). In his book Moral Panic: Changing conceptions of the Child Molester in North America, Jenkins (1998) points to sociopolitical and economic factors such as Thatcherism, immigration, unemployment and gay liberation as a basis for this social anxiety. Social anxieties emerging from these and other sites are often resolved in a symbolic confrontation between a deviant "them", and an imagined ideal community constituted as an "us".

This ceremonial clash can result in the clarification of normative boundary lines demonstrating that there is a limit to how much diversity society can tolerate (Goode and Ben-Yehuda 1994:29). Significantly, panics are modern products that suppose a certain functionality, to strengthen and redraw moral boundaries (Durkheim 1964), or at least point to where boundaries are too weak. When society's moral boundaries are clear and sharp, moral panics do not emerge, as norms and values are generally shared among the 
social group. It is only when boundaries become contested that panics strike (Goode and Ben-Yehuda 1994:52). In this, the variation and instability characteristic of the late modern period is recognizably ripe for the emergence of moral panics.

For instance, according to Critcher (2006), another underlying dynamic of moral panics is found in generalized feelings about rapid and uncontrolled social changes that characterize late modern societies. Profuse social anxiety becomes a symptom of moral decline, so out-group activity, which may have little to do with the general social patterns of instabilities, becomes a localized object of resentment, thus becoming symptomatic of a folk devil (8). It is a familiar psychological process where anxieties become displaced from their original source and projected onto simple targets, those who have already been subjectively condemned as deviant (such as youth, or sexual deviants). Members of society separate parts of the collective self that are evil and project them onto an outside group, a process known as splitting and projecting, or scape-goating (Goode and BenYehuda 1994:65). Thus, moral panics are a means of generating ideologies of cohesion that can override other forms of difference (which may include race, gender, class or religious affiliation).

\section{2- Sex Panics}

Moral panics are not specific to youth violence and drugs. Indeed, a particular and especially potent version of moral panic is the sex panic (Thompson 1998:73) as examined by Jeffrey Weeks (1981), Gayle Rubin (1985) and Phillip Jenkins (1998) in the exploration of issues such as HIV/AIDS in America, childhood sexual abuse and child pornography panics. Indeed, Western culture has been characterized as a society shaped 
through a history of recurring sex panics (Burgett 2008:1); historically, sexual spectacles incite fearful feelings and a sense of danger to society (Herdt 2009:15), but also serve to solidify the boundaries "undesirable" and "desirable" sexuality. As examined in the work of Foucault (1978) and Weeks (1986) sex has been produced as a site of particular importance in western society. Sex, perhaps unlike any other field of life, is thought to speak the truth about ourselves and express the "essence" of being so it's easy to see how it has become an instrument expressive of social anxiety and therefore an area wrought with emotion. Especially in modern life we see how concerns over the social order get projected onto this "essence", thereby reproducing sex as an instrument expressive of social anxiety.

With the explosion of discourses around sex and sexuality came a desire to manage and regulate it (Foucault 1978), resulting in notions of normal and abnormal behaviours. Moreover, sex is deployed as a way of constructing the "population" and is developed as a naturalistic framework through which moral, legal, health and other social bonds are connected. Transgression of sexual norms became pathologized resulting in an ideological polarization, and a clear division between those who did not conform to heternormativity, and those who did. The rise of distinct perversions, which some researchers believe lay at the heart of western constructions of sexuality (Dollimore 1991), provided the opportunity to construct oppressive sexual norms that were used to police sexual life (Kinsman 1994:167). This regulation of norms inevitably produces "an other", the subject of alterity, towards which we direct our fear. Similar to the moral panic literature -in that the goal is curtailment and management of a problem behavior, in the modern period, sex panics are a means of inflicting structural regulation on categories 
of people. By examining what she called "sexual hierarchies", or ideologies, including those of medicine and contemporary thought, Gayle Rubin (1985) raised critical questions about the role that normativity and cultural anger play in the management of sexuality in societies:

All these hierarchies of sexual value-religious, psychiatric, and popular-function in much the same way as do ideological systems of racism, ethnocentrism and religious chauvinism. They rationalize the well-being of the sexually privileged and the adversity of the sexual able. It is difficult to develop a pluralistic sexual ethics with a concept of benign sexual variation. Variation is the property of all life... Yet sexuality is supposed to conform to a single standard. One of the most tenacious ideas about sex is that there is one best way to do it, and that everyone should do it that way (108).

Sex panics emerge then, when normative sexual boundaries are transgressed, when certain sexual behaviours compromise the moral fiber of a society. In this view the sexual folk devil or "sexual other, whether oversexed or undersexed is stripped of rights and the cultural imagination becomes obsessed with anxieties about what this evil sexuality will do to warp society and future generations" (Herdt 2008:5). Although similar to the moral panic literature, the sexual folk devil stand as a particularly evil and dangerous conceptualization (due to its alignment with sex and sexuality) and needs to be given special attention within the panic literature.

\subsection{Media and Panic}

The media plays a significant facilitating role in all instances of moral and sex panics. In fact, Critcher (2002) argues that, "modern moral panics are unthinkable without the media" (131). The panic surrounding the $2010 \mathrm{HPE}$ curriculum reflected this, as the Ontario debates were articulated largely through media representation and it was only 
through this medium that many concerned parents and citizens received information regarding the curriculum. It is important to explore the role of the media in perpetuating general panics before I look at the specific role of Canadian media in disseminating information related to the HPE curriculum specifically.

In advanced industrial societies, Cohen (1972) argues information about what constitutes criminal, sick or otherwise deviant behaviour is often received second hand, largely through the media. The ways in which certain issues are reported, or not reported, reveals how the media comes to define and shape social problems (Cohen 1972:7). Citing Erikson (1966), Cohen notes, "a considerable portion of what we call 'news' is devoted to reports about deviant behaviour and its consequences" (8), which in turn helps to shape the normative boundaries for acceptable social action and behaviour. More importantly, Cohen contends that "the media have long operated as agents of moral indignation in their own right- even if they are not self-consciously engaged in crusading or muckracking, their very reporting of certain 'facts' can be sufficient to generate concern, anxiety, indignation or panic" (10). In other words, the way in which the media construct social problems not only helps to define and organize social problems, but can simultaneously challenge society's normative boundaries. Thus, for Cohen (1972), the panic surrounding the Mods and Rockers was a product of how the mass media constructed that particular social problem. In large part it was the story that was reported that made possible the moral panic, not the existence of any actual physical threat.

One of the most notable examples of the effect of harmful mass media on susceptible audiences concerns the radio transmission of H.G Wells', "War of the 
Worlds". Aired in October of 1938 , the broadcast was a fictitious radio drama about the invasion of the earth by aliens. Despite repeated announcements of its fictitious nature, many people believed the broadcast to be of a real Martian attack. Both during and after the broadcast, it was reported that mass panic erupted; claims were made that people all across the country fled their homes, called their loved ones for tearful farewells and a few even committed suicide. Of the approximately six million people who listened to the broadcast, it was said that over one million of them were overtly frightened or disturbed (Cantril 1966:47). However, these sensational accounts of mass panic were later discredited (see Bottomore 1999). Such claims stand as a "powerfully resonant metaphor for the belief that the modern media are capable of exerting harmful influences, or triggering mass outbreaks of negative social consequences and of causing damaging psychological effects" (Jewkes 2004:10).

Based on the myth of the "panicking audience", researchers became interested in the way in which media brings these fears to life. Cohen (1972) stands out as a significant contributor to the role of the media in the manufacturing of fear. In his analysis of the Mods and Rockers, Cohen discusses the way in which the mass media fashioned the episodes, or stylized them, amplifying the nature of the facts and consequently turning them into a national issue, when the matter could have been contained on a local level. Based on his initial assessment, he scrutinized the media inventory and found that media uses three "tricks" to orchestrate fear in audiences: exaggeration/distortion, prediction and symbolization.

\section{Exaggeration/ distortion:}


Based on his analysis of the Mods and Rockers, Cohen found that the media exaggerated not only the number of youths taking part in the troublesome behaviour, but also distorted the amount and type of damage that was done. The media also sensationalized the story by using an overtly cacophonous vocabulary aimed at heightening the negative aspects of the story, the issues that were considered newsworthy (Thompson 1998:33). Words such as "riot", "screaming mob", "siege" and "battle" were frequently used by the media, and misleading headlines that were discrepant with the actual story were commonplace. According to Cohen (1972), the repetition of false stories is a familiar finding in studies that examine the role of the press in spreading mass hysteria (21). In reporting on the Mods and Rockers, stories of the damage to the community was heavily overestimated and frequently repeated. For instance, only $10 \%$ of the youth who were arrested were charged and not all charges were violent: some were charged with things such as stealing drinks from a vending machine or taking a half pint of petrol (Cohen 1972:37). In other examples, newspapers ran stories stating that all the dancehalls in town had been destroyed, however, Clacton only had one dancehall and although its windows were broken, no other damage was done.

\section{Prediction:}

Part of Cohen's analysis included an examination of the media prediction that the violence attributed to the youth would be followed by more events, with even worse consequences. Similar events in other English villages did in fact occur; however, these were more localized and involved fewer people and less damage. Despite this, media reports suggested that the problem of youth violence was on the rise. The youth violence 
and vandalism stories that ran in the press during the years following, used a stereotypical format: the actual event had very little to do with the ensuing stories. Instead, those who perpetrated "harm" were presented as dangerous, violent gang members and troublemakers. There was very little interest in what actually happened, so that over time, a number of central elements to the story of youth violence came to indicate a risk to the social order, rather than narratives about particular events (Goode and Ben-Yehuda 1994:25).

\section{Symbolization:}

According to Cohen (1972), "there appear to be three processes in symbolization: a word (Mod) becomes symbolic of a certain status (delinquent or deviant); objects (hairstyle, clothing) symbolize the word; the objects themselves become symbolic of the status (and the emotions attached to the status)" (40). A consequence of this symbolization is that people become sensitized to a certain symbolic economy of threat. Incidences and events that may otherwise have nothing to do with the initial fears are then incorporated into this economy as signs of impending risk to the social order. Accordingly, seemingly unrelated phenomenon, such as a bar fight, or adolescent play can be interpreted as related and part of a wider social problem (Thompson 1998:36).

As public nervousness increases, agents of social control such as the police and criminal justice system increase their presence while courts begin to prosecute more cases. Thus, efforts are often made to broaden the scope of law enforcement based on the enormity of the perceived threat to society. Eventually the formation of community action groups and moral entrepreneurs may emerge. Moral entrepreneurs describe people 
who perceive a threat to their own commercial interests by the problem group. Often moral entrepreneurs work to extend the local coverage of the problem event to include national media.

\section{4- Media, Sexuality and Youth}

The mass media plays an enormous and sometimes paradoxical role in spreading fearful sexual imagery and ideas far into a culture (Irving 2005). "In media representations, sexual panics may generate the creation of monstrous enemies- sexual scapegoats... which dehumanizes and strips individuals and groups of people of sexual and reproductive rights" (Herdt 2009:3). Take for example, the sexual scandal surrounding President Bill Clinton in 1998; the world was saturated with shocking details of the extramarital affair Clinton had with then intern Monica Lewinsky. Concepts such as "oral sex" and "adultery"- previously too taboo for the mass media to discuss- became the topic of everyday print and fanned on television, radio and the Internet (14). Opponents of Clinton even suggested impeachment for his affair, creating a cultural spectacle around the private life of a citizen leader. The purpose of such an exaggerated reaction, then, is to incite new kind of talk and action and re-draw and make visible sexual boundaries and limitation (Elder 1975:14). Here a relatively esteemed individual became a sexual degenerate almost overnight in large part due to the mass media's reporting on the issue.

The news media also has an immense interest in youth sexuality (Taylor and Willis 1999), and one way in which to understand media coverage of youth sex is through framing, first introduced by Goffman (1974). News frames tend to simplify, prioritize, and structure the narrative flow of events (Tuchman 1978) by providing a particular interpretation of an event or fact. The mass media has the ability to shape knowledge by 
ascribing ideological traits to events, individuals, and spaces, which maintain the status quo. For instance, critical scholars have long emphasized the role of mass media in perpetuating an essentialist construction of adolescence. Deterministic theories supposing an inevitable developmental duration of impulsive urges, sexual insatiability, delusions of invincibility and psychological "storm and stress" have all achieved popular acceptance, encouraging the promulgation of discriminatory narratives, and the construction of youths as objects to fear and fear for (Giroux 2003; Mazzarella 2003).

Prior to the early 1990's, youth were depicted as victims in need of protection, due to the physical and sexual abuse suffered at the hands of adults. Although this discourse still persists, it now stands alongside paradoxical discussions of dangerousness as the murder of a child by children occasioned a significant turning of the tide, and young people came to be seen as potentially evil and criminal (Lehr 2008:209). Thus policies intended to contain and control were put in place. Today, what is actually written about youth sexuality in the Canadian media is often negative and extremely critical. There is an implicit bias in the mainstream media that perpetuates a conservative view of youth sexuality and presents it as something that is wrong and needs to be prevented, impeded or terminated.

Media coverage of youth sexuality is often sensationalistic and fear-mongering, which sends communities into a panic (Bruner 2003; Jackson and Scott 1999). For example, Newsweek's "Teens and AIDS" (8/3/92), Time's "Kids, Sex, \& Values" (5/24/93) and U.S. News \& World Report's "Teenage Sex: Just Say Wait" (7/26/93) all featured stories of young people accompanied with commentary on sexual irresponsibility among schoolboys and girls. Time and U.S. News both blamed "teenage 
sex" on "confused" kids, and held up abstinence education as the cure. There is a pervasive attitude reflected in the media that youth are controlled by hormones and can only make reckless, senseless decisions about their own sexuality and sexual behavior (Bruner 2003). Due in part to the media's and popular culture's continued utilization of sensationalism to attract customers (Surette 1992), the general public has developed a "discomfort" with youth, and in particular, youth sexuality.

According to Cohen (1972), subjects of moral panics are indeed important, but it is societal responses to particular issues that constitute the chief problem (Welch et al. 2002:22-23). With this in mind, the societal response to the topic of youth sexuality appears to have been to categorize and stigmatize youth. Representations of the dangerousness of youth date back as early as the Victorian era, a time when underprivileged youth were considered "street urchins" who threatened societal development (Hebdige 1988). Today, it is through these representations of youth as "outsiders" that they continue to be ideologically separated from the "adult world". They constitute a unique and polarized group being both $a$ risk to cultural betterment and $a t$ risk of sexual and moral corruption; therefore a group that needs to be both regulated and protected (Jackson and Scott 1999).

\section{5-Concluding Remarks}

The concept of moral panic has enjoyed a rich history in sociological literature. Since Stanley Cohen (1972) published his seminal study on the Mods and Rockers, scholars have used the concept of moral panic to identify and explain disproportional and exaggerated societal reactions to perceived threats to the social order posed by some 
condition, episode, person or group of people. In other words, the concept of moral panic denotes the processes by which the representation of harm embodied in a folk devil becomes viewed as a major threat to social values, interests or even the very existence of a society.

In this chapter, I have used the work of Stanly Cohen (1972), Goode and BenYehuda (1994) and others to provide an understanding of the calculable measures of a moral panic, and more specifically, of a sex panic. I have also explored the role of popular media in perpetuating a panic and illuminated popular media constructions of youth sexuality. According to the moral panic literature, the claims regarding the potential harm embodied in the folk devil enter the mass media, which then disseminates the claim to the general public. At this point, the threat comes to be seen as more menacing and problematic than it really is, stimulating widespread feelings of social anxiety and concern.

This chapter, then serves to review the literature surrounding youth, sex and media but it also provides a conceptual apparatus for identifying the ways in which media facilitate moral panics. I will return to this framework again in chapter four to illuminate the ways in which the HPE panic was articulated, but first, must examine some of the social and moral context that allowed this panic to emerge in the first place. 


\section{Chapter 3- Theoretical Frameworks}

In popular discourse, youth and teenager are used interchangeably to refer to individuals who are passing from childhood to adulthood, maturing and developing an emotional, physical and intellectual maturity that is necessary to be a productive adult citizen. Along with this transition, it is assumed that sexual maturity must develop in order to procreate and ensure the perpetuation of Western culture. Children often become the focus of innumerable projects that purport to safeguard them from physical, sexual and moral danger to ensure their "normal" development throughout this process (Egan and Hawkes 2008:196). However, youth are also commonly represented in popular discourse as a troublesome group in need of regulation, due to their precarious position as existing somewhere between a child and an adult. In this chapter, I will explore the concept of "youth" and the anxieties that exist around the transition from child to adult. Drawing on the work of Neil Postman (1992) and Stanley Hall (1904) I will show how cultural betterment and social progression have been tied to the proper (heterosexual) pathway from childhood, youth and adulthood and how "youth" has become a category wrought with anxiety in Western culture, due to this transition.

I suggest that a review of the social construction of sex, sexual deviancy and the category "youth" is particularly important to an understanding of the moral panic that developed in response to the proposed sex education curriculum. Hence, I will advance existing theoretical frameworks by drawing on the work of Michel Foucault $(1972,1978)$ for both a theoretical understanding surrounding the discursive explosion of sexuality, as well as to establish an understanding of sexual regulation for dissident sexualities. I will show how Foucault's critique of the repressive hypothesis is equated in the scholarly 
literature with the idea that sexuality and sexual identity formations are "socially constructed," and therefore in order to study sex, one must commit to denaturalizing received ideas about sex and sexuality across a particular time and space. The novelty of the emergence of "youth sexuality" then is specific to a certain historical juncture, and must be examined within a particular context.

\section{1- The Social Construction of Sex and the Emergence of the Sexual Deviant}

The history of sexuality since the mid- $18^{\text {th }}$ century has often been read as repressive. Since the rise of the conservative bourgeoisie, who were socialized to hide their bodies, any expenditure of energy on pleasurable activities has been frowned upon. Sex was constituted as a private affair that took place between a husband and wife, and only for the purpose of procreation. Yet, as Foucault argues, this was the very moment when sexuality became something special (1978:3-13).

Sex became something that had to be managed, to "function according to an optimum" (24). In order to gain power over sex, a refined language was developed to control it in everyday speech and "extinguish the words that rendered it too visibly present" (17). The restrictive economy of language around sexuality was meant to produce a cultivated society, and sex outside of the limited confines was not only frowned upon, but restricted. This restriction however, had the effect of producing a proliferation of discourses concerned with sex. According to the repressive hypothesis, certain outlets, such as prostitution, where improper sexual urges could be released safely were produced and Foucault identifies prostitution and psychiatry as examples. He refers 
to those who engaged in either as "the other Victorians" (3), those who existed in an alternative discourse on sexuality, beyond the zones of "the normal" (3).

Emergent from this new emphasis on sex was the multiplication of discourses produced on medicine, psychiatry and criminality; all played different roles in the diffusion of knowledge on sex, however, all were interlocking (17). Religion once determined what was moral and immoral, yet over time these were rationalized into scientific notions of "normal" and "abnormal" made possible through the development of institutions such as psychiatry, criminality and education.

Each of these fields contributed to normative discourses seeking to regulate sexual life. Certainly, it is commonplace to associate sexual repression, as a response to these discourses, with the Victoria period. However, it would be a mistake to assume that sexual repression defined Victorianism as an absence of sexual activity. In fact, social institutions, which sought to organize, define and regulate moral and social life, contributed to the proliferation of sex. For instance, sex and sexuality were considered in the design of schools and dormitories. With the aim of regulating and controlling sex, sexual discourses increased, intensifying people's understanding of sex as a social danger. In this way, Victorian life was characterized by a rapid growth and diversification of sexual forms (28).

People wanted to talk about sex, agencies wanted to hear it spoken about and everything had to be told. Although certain words were forbidden, Catholic confessions about sexuality increased and everyone talked, as often as possible about sex; there was even an increase in scandalous literature, in the form of poetry and books describing sex in exacting detail. The censorship of language was simply a way of rendering it morally 
acceptable to discuss in the private sphere. Whether in the form of a confession (in confidence) or an authoritarian interrogation, sex was put into words (32).

\section{Categories of Sex: Perverts and the Rise of Sexology}

Beginning in the $18^{\text {th }}$ century, there was a political, economic and technical incitement to talk about sex. It was analyzed, classified and quantified to "develop a discourse that would not derive from morality alone but rationality as well" (32). This was the first time that societal future and fortune (population numbers) was tied to how its citizens made use of their sex. Sexuality became a privileged site for approaching and understanding the origins of human society (Weeks 1986:15). Regulation favoured an increased birthrate, so systematic campaigns were carried out to transform sex into an economic and political behaviour in order to promote procreative heterosexuality. Language was used to subjugate dissident (homo) sexualities: desire was transformed into discourse (religious and pseudo-scientific) in order that it be controlled (Foucault 1978).

With the establishment of a contaminative sexual model, legal sanctions against minor perversions were developed and sexual irregularity was annexed to mental illness. For instance, from childhood to old age, a (hetero) norm of sexual development was defined and all possible transgressions were carefully described and controlled (Weeks 1986:36). With the rise of the scientific model, irregular sexuality drew the attention of "science" resulting in the "incorporation of perversions" and the "specification of individuals"; one's sexual proclivities constitute not just the acts of the body, but the key to unlocking one's character. This is exemplified in the work of Krafft-Ebing (1928), the sexologist who identified hundreds of psychiatric disorders emanating out of sexual 
deviancy. This led to a rigid inscription of "the normal", while the disease model linked sexual "perversions" such as homosexuality and underage sexual practises to concepts of pathology, sickness and madness (Weeks 1986). Sexuality, and sexual deviancy, has been produced as a site of particular moral importance.

During the $19^{\text {th }}$ century, "sex and sexuality began to organize political discourse and everyday practise, in large part by marginalizing, translating and reconstructing other residual and emergent discourses concerned with the political and ethical relations among bodies..." (Burgett 2008:4). The Victorians then, were the start of a tradition, which we find ourselves today; an emergent social and political force where sexuality is a defining force in delineating one's identity.

\section{2-Youth Sexuality}

\section{Social Construction of Youth}

Although discourses on childhood and youth have exploded in the $20^{\text {th }}$ century, there is no consensus or clear definitions of either. Traditionally age has been used to determine these categories, however with the rise of conflicting and contested discourses, age is no longer a clear boundary marker. Age has been replaced thus, by more fluid characteristics such as individual assessments of sexual maturity and innocence. Youth no longer exist as a distinctive category separate from adulthood, which has ultimately led to anxiety surrounding youth sexuality and what is acceptable in terms of appropriate behaviours.

Traditionally, psychology dominated the discourse around youth, as modern, scientific conceptions represented a developmental view of the progression of children to adult and "... in the guise of developmental psychology, firmly colonized youth in a pact of medicine, education and government agencies" (James, Jenks and Prout 1998:17). 
In popular opinion, childhood has been defined by age with most people viewing a child as being a person under the age of twelve (CASA 2007), where they then become a teenager, and finally at eighteen, an adult. These categories however are highly contested and in contrast to the popular developmental narratives of youth, sociological research emphasizes the relatively recent historical, cultural and social construction of adolescence. These socialization theories grant more significance to social processes, but many continue to analyze youth in relation to a teleological understanding of the requirement to accomplish adulthood. For instance, the essentializing framework of Hall (1904) provided scientific legitimation for a socially engineered extension of childhood (Lesko 2001) in order to become productive adults.

\section{Adolescence as a Post-Child and Pre-Adult Discourse}

Childhood is a modern social category: in Ancient Greece, very little attention was paid to children, and it was not until the introduction of mass education and literacy that childhood was born (Postman 1982:7). According to Postman, the distinction between children and adults was originally determined based on differences in knowledge, and particularly the capacity to read. As such, modern notions of childhood emerged out of notions of innocence, particularly that they were unable to access the meanings generated in popular texts. The idea of childhood as being a period of human innocence and naïveté has been maintained and continues to inform current perceptions of children as pure and unpolluted by political, economic and especially sexual knowledge. For this reason, moderns consider the place of childhood, and children themselves as needing to be sheltered from adult secrets, especially sexual ones, and thus, "a conspiracy of silence 
concerning sexual urges is maintained in the presence of the young" (9). Certain facets of life, such as violence, tragedy and mystery are not suitable for children to know, if innocence is to be protected.

However, with a decline in literacy in the Dark and Middle Ages, equality emerged among children and adults. Postman argues that something akin to a loss of childhood has emerged in the $20^{\text {th }}$ century, as a result of the ubiquity of visual media, judicial legislation and children's access to knowledge. He contends that the adult child who was common during the Middle Ages has reasserted itself in contemporary society in the form of the adolescent. This social category may be defined as "a grown-up whose intellectual and emotional capacities are unrealized and, in particular, not significantly different from those associated with children" (99).

With the increase in image driven television commercials catered towards the lowest common denominator, the boundary between children and adults have diminished, while the incidence of "adult children" has risen. Pictorial and narrative modes are of a lower order of complexity and maturity that the expository, thus Postman argues that living in a culture that is dominated by pictures and stories, and which has no capability of revealing the continuity of time and space, has resulted in the homogenization of mentalities, thus children and adults have merged, to form the adolescent (117-118). "Everywhere one looks, it may be seen that the behavior, language, attitudes and desireseven the physical appearance- of adults and children are becoming increasingly indistinguishable" (4).

According to Postman, in media representations it is evident that children have virtually disappeared from television and even when they are shown, they are depicted as 
miniature adults (122). Often they do not differ significantly in their interests, language, dress or sexuality from adults, a process he refers to as "adultification" (124), while simultaneously the "childified" adult is becoming more prevalent. The majority of adult representations on television are depicted as functionally illiterate, have no foresight or long term plans, do not take their work seriously and often never allude to anything that is not familiar to an eight year old viewer (127). We are thus rapidly undergoing a transformation in popular culture in regards to images of children and adults merging to form teenagers.

As language, clothing, tastes and eating habits (to name a few) become increasingly homogenized between adults and children, there is a corresponding decline in both the practice and meaning of civility, which is rooted in the idea of social hierarchy. Within social modernity, adults have lost most of their authority, and the idea compliance to one who is older has become increasingly obsolete (132).

\section{Post-War Discursive Constructions of Youth}

The prolonging of childhood was a distinctive marker of the postwar world, a signal that grown up worries could be kept at bay for a good part of life. Teens were seen to live a carefree life with more choice and less responsibility; they were not expected to make any significant decisions, or even be capable of doing so, in fact most of their freedoms were contingent on adult approval (Adams 1997).

In the post-war period there were many competing discourses about youth, as the notion of adolescence as a time of rapid and profound change operated as a funnel for fears about change in society at large (Adams 1997). Youth operated as a creative 
metaphor for the development of society, as the proper progression from childhood to adulthood indicated a healthy society.

Prominent views emerging from these discourses indicated that teenagers had a growing economic independence (from wartime wages) and a lack of parental supervision, which collided into notions of juvenile delinquency and more generally, a "youth problem". Absent parents, as well as other breaks in normal family life emerged as resonant explanations for the youth problem and delinquency (Clark, Hall, Jefferson and Roberts 1976). Eventually, the changing shape of popular culture (television, dance music, Hollywood movies and crime comics) came to be seen as influences capable of corrupting youthful innocence, and threatening not only young lives, but of society as a whole (Hall 1996).

Although modern family discourse and the entertainment industry played a pivotal role in the emergence of youth as a distinct social category, none resonated as loudly as the emergence of a commercialized teen culture: 'teen magazines, rock ' $n$ ' roll, teen films, teen columns in newspapers, teen sections in department stores were all products of the 'discovery' of the teenager" (Adams 1997:42). This spread in mass consumption constituted "distinctive teenage spending for distinctive teenage ends in a distinctive teenage world" (Abrams 1959:10). The "stylistic invasion" (Clark et al. 1976:20) of unique teenage dress marked an important transition in the arrival of the youth consumer, and creation of a distinct youth subculture. It was this moment that the teenager came to refer to a particular developmental period marked by risk, as well as an age (Adams 1997). 
Along with the invention of youth, came the extension of higher education and age specific schools (the separation of elementary school children from junior high and high school aged youth). This increase in the amount of time spent in institutions with others of the same age had two different consequences. The first was that it enabled the unique conditions for a specifically adolescent society (Clark et al. 1976) and the second, a desire to study and understand the symbolic transition between adult and child. As teenagers stayed in school longer, they became the research material for curious professors, as numerous disciplines, including psychology, sociology and psychiatry attempted to define and understand the boundaries of "normal" teenage development, which included, sexual development (Adams 1997).

Stanley Hall (1904) saw adolescence as a stressful, instinct driven transitional stage between childhood and adulthood and his theory of recapitulation attempted to regulate this stage by linking adolescence with cultural betterment, and thus developing a plan to redirect sexual energies to productive activities in society. Youth offered something no adult could: a condition that must be protected and could be made predictable (Romesburg 2009). The child was conceptualized as malleable, and therefore sex instruction in its attention to both biological reproduction and character training sought to shape the population of the future and manage the individual child (Hall 1904:57). For Hall, the development of the individual paralleled the development of the human race and he insisted that misbehavior and eccentricities of young people be viewed as normal outgrowths of biological maturation rather than inexcusable departures from a fixed, standard behavior (Adams 1997:44). As Lesko (2001) writes:

Adolescents were identified as having great potential but also as being liable to go astray, imagined as ships without stable moorings or rudders, sexually charged 
beings who needed to develop character, responsibility, manliness and focus... Adolescence is a technology to produce certain kinds of persons (49-50).

Hall firmly believed that as the biological individual evolved, so would the rest of society. What made his theory unique however, was the emphasis on youth as the key to racial and cultural betterment. Adolescent development became a useful way to talk about and strategize for racial progress, male, patriarchal dominance and national strength and growth (Lesko 2001:6). Although he was heavily criticized, the incitement to explore the developmental aspects of adolescence only served to intertwine youth and sexuality; sexual regulation was central to the construction of youth, and the "youth problem" was on some level was imbued with sexual meaning, and sexual problems were understood to be problems of youth (Adams 1997). Although the focus for youth was to learn to control appetites to create a self dominated by reason and independence, sexuality was considered a primary desire that needed to be controlled.

\section{3- Managing Youth Sexuality}

Most nineteenth- and early twentieth-century discourses constructed youth sexuality as "actual in its manifestation but hidden in its eventual effects, whose pathological seriousness would only become apparent later" (Egan and Hawkes 2008:198). This was due to the idea that the body of youth --and their sexuality-- provided a gateway for rational control and direction in the advancement of future generations (Hall 1904). According to Foucault (1972), there is no power that is exercised without aims and objectives. The management of the sexual sensibility of the youth offers a twofold benefit: it can shape the present social condition, as well as mould the future in its 
facilitation of a more robust and hygienic population (Egan and Hawkes 2008). Managing youth sexuality; then, serves as a regulatory mechanism, in which multiple aspects of life become potential sites of divergence.

Any divergence from a conservative view of sexuality is seen as a menace and corrupting force, the precocious youth (whether male or female) is capable of contaminating not only the future life of the adult but also the sanctity of the race and nation. Dangerous and deeply problematic, the desiring or autoerotic youth has traditionally been subject to surveillance, classification and often, medical intervention (Egan and Hawkes 2009:57). Autoerotic activity in childhood was thought to be both an inevitable outcome as well as a site of deviance in need of control, simultaneously natural and a result of pathology (Foucault 1978). Purity activist Elizabeth Blackwell, for example, cautioned parents on the dangers of sexuality in children in her 1884 Counsel to Parents on the Moral Education of their Children in Relation to Sex. Blackwell emphasized the importance of childhood innocence, but also insisted that a child's sexual instinct, if not controlled, could gain "undue prominence within the life of the child" (Blackwell 1884:15).

Enlisting parents and relatives to be on guard against the precocious sexuality of youth reproduced this same goal. It was feared that both girls and boys introduced too early to sex would be transformed into delinquents and problem youth, so the entire family could then be implicated if problems arose. Parents were blamed for the sexual sins of their children, and in turn parents who practiced a healthy or moral sexuality could expect their children to do the same. Healthy or uncorrupted sex became a mark of pride 
for the bourgeois (McWhorter 1999:27-30). Normal adult sexuality, then, was an achievement and marked a safe passage through adolescence (Adams 1997).

During the postwar years, youth were the target of a range of formal and informal sex education material, sites in which mainstream norms were both constituted and reproduced, as the importance of "normalness" to postwar social organization made sexual transgressions an issue with grave consequences (Adams 1997). The relationship between discourses about sexuality and discourses about youth helped to establish the boundaries of normal. The fear of being labeled a sexual deviant was an effective form of self and familial regulation, a threat to those who might transgress sexual or moral standards. Discursively, sexual delinquency worked to control expressions of sexuality and to justify the regulation of all young people (82).

Today, there are numerous mechanisms in place to manage youth sexuality. It is regulated and controlled not only through familial and social interactions and expectations, but also through formal legislation that governs legal and social institutions (Rubin 1985). Tied to the moral conservativism and traditional assertion that sex is only to occur within monogamous relationships, youth have become the target for a number of regulatory measures in order to ensure the normal progression toward becoming productive adults. Moreover, sexuality has been framed as "adult-only" because youth are assumed to lack the proper level of maturity and agency to fully understand the repercussions and dangers of these sexual activities.

There has been a distinct trend in social modernity in which discourses of regulation stand alongside those of protection, as the last two decades have seen a monumental increase in the amount of sexual imagery, content and consumer practises 
that are directed towards children and youth. Historically, children and youth were seen as a vulnerable population in need of shelter from adult sexual matters, yet North American culture has now come to fetishize this vulnerability, innocence and childhood as objects of sexual desire, thereby challenging the discourses of innocence and chastity typically associated with young people. This has created a panic of sorts, and has led to a rigid reproduction of children and youth as a group needing protection from the danger of adult sexual matters, if they are to continue to be pure.

In 2010, the American Psychological Association's Task Force on the Sexualization of Girls reviewed dozens of studies and determined that sexual images are found in virtually every medium, from TV shows to magazines and from music videos to the Internet. For instance, one content analysis found that sexual content (which ranged from flirting to sexual intercourse) had increased from slightly more than half of television programs in 1997-1998 to more than two thirds of the programs in 1999-2000 and that depictions of intercourse occur in one in every ten programs (Kunkel et al., 2001). Hollywood makes approximately 400 films a year, (two thirds have an R-rating or higher [although not always related to sexual content]) while the pornography industry makes between 10,000-11,000 (Williams 2004:1-2); there is no contestation to the quantity of sexual images now readily available for those with the technologies to access them. One study found that "children" and "youth" (aged 8-18) spent an average of 6-7 hours a day with some form of media, thus it is impossible to ignore how often nonadults are potentially exposed to sexual images (Roberts 2000).

However, the widely felt fear around protecting children from pervasive sexuality is not simply about the availability of sexual images, but the ways in which sexuality is 
marketed to children and youth. While the exhibitionists antics of Paris Hilton and the Pussycat Dolls mesmerize small girls around the world, retailers like Abercrobie and Fitch carry thong underwear for 10 year-olds with seductive slogans like "wink wink" and "eye candy" and French maid costumes, garter belts and low cut jeans are now available in preteen sizes. According to Durham (2008), we are seeing "increasingly adult content being aimed at young children [which is] why dolls sold to preschoolers look exactly like the half-dressed women in music videos and soft-core men's magazines and why toddlers fashions are almost indistinguishable from those of teenagers" (30). Girls in particular, are being marketed products and images that promote looking and acting sexy, a practise that many believe is negatively impacts girls' "cognitive functioning, physical and mental health, sexuality, and attitudes and beliefs" (APA 2010:2). In fact, the ubiquitous eroticization of children characteristic of modernity has been linked to three of the most common mental health problems of girls and women: eating disorders, low self-esteem and depression (APA 2010:18). Overall, there is a plethora of evidence to support the thesis that the sexualization of children and youth can negatively impact the ability to achieve mental, physical, and sexual health, however paradoxically, the sexualized child/youth is alluring and an effective consumer tool. This has led to a tenacious cultural rhetoric that insists on the protection of the vulnerable and innocent youth in order to protect them from the dangers of pervasive sexualization.

\section{4- Concluding Remarks}

Youth have been identified as a distinct social group with unique culture and experience (Bay-Cheng 2010). They are conceived as a group in transition between children and 
adults and they are thought to offer a unique link between individual and species development (Hall 1904). However, by reason of their ambiguous age categorization and close relation to childhood, they also serve as a group in need of protection from adult sexual matters.

In this chapter, I have used the social constructionist framework to explore the isolation and construction of "youth sex" as a particularly intense hub of social anxiety. I have done so, by examining both the constructions of "sexuality", characteristic of Foucault $(1972,1978)$ and the ways in which "youth" are understood within modernity. I have also explored the contemporary context that promotes a widespread fear around the increasing sexualization of children and youth, through popular culture and consumer practises. In this, I have highlighted the tensions and paradoxes that exist within the intersection of youth and sexuality, specific to social modernity.

In using the constructionist framework, I have shown how youth have become an important device in the regulation of adult matters and due to the linkages between youth and sexuality, it is considered particularly important for his group to be managed, if Western culture is to thrive. In the following chapter, I will explore sex education as one way that youth are managed and use the HPE curriculum to illuminate the particular anxieties that are felt around "youth sexuality". Here, I will make reference to the transition from religious and community organizations to scientific rationale in regulating sexual life and how this transition creates instability and moral decline for some. 


\section{Chapter 4- Health and Physical Education as a Moral Panic}

As I touched on in the previous chapter, the sources of sexual socialization for youth are numerous and can include peer attitudes, family values and media exposure. However it is with sexual education in schools that our society makes its most concerted attempt to employ a public institution to socialize youth with regard to the sexual norms and mores of our culture (McKay 1998:26). If youth are seen as the conduit for cultural betterment and development, their sexual education can be used as a guiding mechanism for social survival. Sexual education serves as a microcosm to which larger sexual and moral debates have emerged, and although the battle of sexual education is in part influenced by educational methodologies, it is a "clash of fundamental values or different ways of seeing the world" (31), and thus a source of discomfort for many.

However, debates over sex and public schooling in Canada have been much more tempered than in the United States where children are featured prominently in campaigns to prohibit same sex marriage and debates around federal funding for abstinence only education are continuous (Rayside 2010). Canadian discussions around sex in schools are much less contentious; one main reason for this is that Evangelical Christians (who represent the core of opposition to any positive portrayal of sexual diversity in the schools) represent between one third and one half of the population segment that they do in the US (3). Nevertheless, there are still many anxieties about the educational politics of morality in the minds of Canadian parents, voters and, to some extent, policy makers. In 2007, political and administrative interest in sexual diversity intensified and consultations began over a new Health and Physical Education curriculum (HPE) in Ontario schools. 
In this chapter, I examine the reaction from concerned parents, members of the religious right and politicians to proposed curriculum changes, and consider the role of the media in constructing an HPE curriculum "event" as part of a larger moral panic. To do this, I examine the sources of discomfort for opponents of the curriculum and explore how the panic was mobilized and perpetuated in mainstream print media in April and May of 2010. Drawing on media reports, moral panic literature and theories of adolescence and sexual deviancy, I demonstrate how opponents of the HPE curriculum framed and legitimized their condemnation of the changes to the sex education curriculum through exaggerated and distorted rhetoric that relied upon powerful symbolic constructions of the innocent and vulnerable child. I will also point to the presence of moral entrepreneurs in framing the debate, who fanned the social anxieties associated with the social construction of youth sexuality.

\section{1- Some Context}

In 2005, the Ministry of Education began reviewing every curriculum that was currently in place in Ontario schools to ensure the content of these curricula was age appropriate and included aspects of equity and inclusive education. In 2007, the Health and Physical Education curriculum came up for review, as it had not been reviewed since 1998. Included in the curriculum were topics such as healthy eating, personal safety and injury prevention, substance use and addiction and related behaviours (Ministry of Education 2010a). Sex education also fell under the purview of Health and Physical Education, and with an increasing social interest in sexual diversity and its link to school bullying it became the focus of extensive consultation and debate. 
During the next three years, approximately seventy groups were consulted, including teachers (both Catholic and secular), parents, student groups, social service providers and government officials, in addition to a systematic survey of active teachers. Recognizing that sexual orientation was one of the top three motivations for hate crimes in Canada and that the second most common locale for such crimes was educational facilities, it was suggested that the new curriculum tackle issues relating to diversity and the persistent homophobic current apparent in both secular and Catholic schools (Rayside 2010). One of the main objectives of the new curriculum was to "connect [children] to the curriculum; that they see themselves in what is taught, how it is taught and how it applies to the world at large" (Ministry of Education 2010a) (italics in original). The proposed HPE document was designed to assist children in making informed decisions in the ever-changing global community.

By late 2009 the final version of the HPE curriculum was ready. The final document made heavy use of pedagogical and instructional language, referring to the sex education aspects of the curriculum as "age appropriate" lessons and provided ways to appropriately respond to student questions. The curriculum was set to begin in grade one, where students would learn the anatomically correct names of body parts (including their sense and functions). Grade two would see students learning the stages of sexual development, and grade three would teach the physical and emotional development associated with puberty, what constitutes a healthy and unhealthy relationships and both visible and invisible differences in identity (such as race, ethnicity and/or sexual orientation). Discussions around puberty would continue into grade four (with a focus on the emotional and social impact of development and personal hygiene including 
menstruation and spermatogenesis and hygienic practices during this time). Children in grade five would engage in discussions around the reproductive system, and grade six students would be invited to participate in discussions around decision-making in relationships and navigating pubescent changes within the context of a healthy relationship. Grade seven students would learn about STI transmission, pregnancy prevention and delaying sexual activity. Discussions around healthy relationships would continue and sexual decision making introduced. In grade eight, contraception, intimacy and sexual orientation would also be discussed in detail (Ministry of Education 2010).

The new curriculum was then prepared for official release; it passed the "four corners" meeting, which brings together a representative of the relevant ministry's top officials, the minister's office, the premier's office and the central senior civil service. After this meeting, the curriculum announcement was posted on the ministry's website. A memorandum was also sent to all school boards announcing its release.

Many people knew about the curriculum; hundreds had been involved in consultations; hundreds of school board officials in both Catholic and public systems knew about it and received copies of it to send through the system to ensure adequate preparation for the September school year. Despite this broad consultation and high level of involvement and support by a range of individuals and groups, there was no sign of discontent or acknowledgement until the March 2, 2010 publication of an article entitled "Mandatory Curriculum in Ontario Schools Promotes Homosexuality, Masturbation" on the site, LifeSiteNews. The article began with the following: "As of next year, Grade 6 students in Ontario publicly funded schools can expect to be taught that masturbation 'is common and is not harmful and in one way of learning about your body'..." Two 
paragraphs later, the story referred to the Ministry of Education's campaign to promote "equity and inclusive education" which included "the advancement of homosexualism and transgenderism... and the attempt to instill a sense of homosexuality and transgenderism are perfectly normal” (Craine 2010).

This would be the first time anything was written regarding the new curriculum. In fact, it would be almost three months after the article that any other form of media even mentioned the HPE curriculum. On April $15^{\text {th }}$, a reporter for the Hamilton Spectator stumbled upon the new curriculum while researching a story around gender equity and sexual orientation policies in schools (Rayside 2010). The paper ran an article entitled "Birds and Bees to be Taught in Grade 3" (see Appendix B) and although it made mention of the standard components of the curriculum --such as delaying sexual activity, puberty and healthy relationships-- it also made reference to some of the most controversial components of the curriculum, including sexual orientation, gender identity and the supposed symbolic loss of innocence that sexual knowledge would perpetuate (Prete 2010). Although this article made reference to many of the "hot spot" issues that would be communicated later on, it did not seem to be aggressively disseminated or elicit a strong response from parents or educators. Four days later; however, Evangelical pastor and activist Charles McVety issued a press release in response to the Hamilton Spectator article denouncing the curriculum and calling for the retraction of the curriculum. McVety was president of Canada Christian College and the Canada Family Action Coalition (CFAC) and a tireless campaigner against abortion and LGQTB rights. His profile was increased by his central role in fighting same-sex marriage, though he had 
also been featured in news stories since then on his purported influence on the Harper government (Rayside 2010).

At 9:00 am on April $20^{\text {th }}$, McVety's press release went out, with the headline:

"Mr. McGuinty, Withdraw Explicit Sex Ed for 8 Year-Olds" (see Appendix C). The press release made references to a website, stopcorruptingchildren.com claiming support from the leaders of family-focused groups with over 100000 active members. Additionally, McVety announced a rally on the Monday after Mother's Day (May $10^{\text {th }}$ ) and encouraged parents to remove their children from school that day. McVety claimed "it is unconscionable to teach 8-year old children same-sex marriage, sexual orientation and gender identity. It is even more absurd to subject $6^{\text {th }}$ graders to instruction on the pleasures of masturbation, vaginal lubrication and 12 year-olds to lessons on oral sex and anal intercourse" (McVety 2010).

In modern societies, most information is received second hand, usually by the mass media, and so subject to their definitions of what constitutes "news". Media pundits often suggest that "sex sells", and images of sensational sexuality are frequently utilized to attract audiences (Dowler 2006). Unlike the Hamilton Spectator article, McVety's press release was laden with a sexually explicit discourse, and journalists likely saw many of the points raised in the press release as "newsworthy" and provocative. In the absence of any government framing of the new curriculum, the explicit language of McVety's press release shaped the ensuing media coverage and subsequent debate. Using Cohen's conceptualization of moral panics, it is apparent that McVety played the role of "moral entrepreneur", framing the debate, generating public awareness of the issue, and creating room for concerned parents, other religious groups and government opposition to 
voice their concerns publicly. Fifty-five hours after McVety's press release, enough attention and outrage was communicated through the media that the Premier announced that the sex education segments of the new curriculum were being withdrawn for a "rethink" (however the vast majority of the new HPE curriculum was still to be put in place by September) (Ministry of Education 2010b)

\section{2- Exaggeration and Distortion}

Recall that Cohen's (1972) investigation into media orchestrated moral panics produced three unique conceptual devices used to construct a panic around a particular issue: exaggeration/distortion, prediction and symbolization. The transmission and diffusion of the reaction in the mass media is, for Cohen, the crucial element in explaining moral panics. Therefore the remainder of this chapter will use Cohen's media inventory to show how opponents of the HPE curriculum constructed their resistance to the proposed curriculum and how popular print media facilitated this resistance. In particular, I will demonstrate how opposition was mobilized around ideas of sexual diversity, the role of the state in defining moral issues and, how the HPE curriculum became a threat to traditional symbols of childhood innocence. The essential point here is that the anxieties and concerns, which were articulated in April and May 2010, took on their most public form through the use of print media by the opposition.

During his investigation into the Mods and Rockers, Cohen (1972) found that newspapers grossly overestimated the story using certain linguistic techniques, like an overtly sensationalistic vocabulary, misconstruing "real" facts, and embellishing the negative features of the situation. These techniques of exaggeration/distortion were 
strongly evident within the data collected around the HPE curriculum debates. For instance, in his initial press release, McVety claims that "it is absurd to subject 6th graders to instruction on the pleasures of masturbation, vaginal lubrication and 12 yearolds to lessons on oral sex and anal intercourse" (McVety 2010). These points however, were not main areas of content, but rather were small components, or "talking points" of the curriculum meant to help teachers approach certain subjects and respond to specific student questions (for a complete list of talking points, see Appendix D). For example, oral sex and anal intercourse were mentioned as examples of the ways in which Sexually Transmitted Infections (STIs) could be transmitted from one person to another (STIs were part of the curriculum in grade seven) and vaginal lubrication was a talking point used in discussions about pubescent changes. The curriculum did not make mention of techniques to produce vaginal lubrication or perform anal sex, or the role of either of these in sexual pleasure and satisfaction. Even so, McVety references these issues as main curriculum content, overemphasizing the role that they would play in day to day instruction, thereby presenting the curriculum as much more explicit and broader in scope, than policy makers had intended.

Cohen (1972) emphasized the importance of the spread of certain beliefs during a moral panic and points out that, for the most part, such beliefs are spread through and by the media. After the Hamilton Spectator article and McVety's press release, the explicit language that was used --particularly by McVety-- was picked up and employed by other opponents of the proposed curriculum changes, as a means of rallying further opposition. Approximately one in five opposition letters to the editor made reference to oral/anal sex, masturbation, lubrication or homosexuality as central matters in the new curriculum. For 
instance, two separate articles in the Toronto Star on April $23^{\text {rd }}$ made reference to oral, anal and vaginal intercourse as part of the elementary school curriculum (Benzie 2010; DiManno 2010) and on April 21, The Daily Gleaner carried an article that made reference to teaching masturbation and oral sex to children (Babbage 2010). According to Foucault (1972), all discourses that get employed by institutions are disseminated in various ways (such as the mass media) and through pronouncements of truth as an ordinary event; we are instructed in ways of thinking, which become constituted in everyday life. It is easy to see, then, how letters of opposition and editorial articles not only were reproducing the exaggerated discourse particular to the HPE curriculum, but also how they were constructing sex as dangerous and youth as vulnerable in a broader sense.

What also emerged from the opposition was the so-called extreme change that the 2010 curriculum content was from the previous 1998 version. The phrase "sexually radical curriculum" (Robson 2010), which first appeared in an editorial in the Ottcwa Citizen was repeatedly referenced in other letters, editorials and headlines, suggesting that a more extreme reworking of the original 1998 HPE curriculum, than was actually the case (Greenberg 2010; Hamilton Community News 2010; Rogers 2010; Thompson 2010). Although the previous HPE curriculum did not contain an explicit "Sexual Health" component, aspects of sex education were included in a "Growth and Development" topic. However, it began in grade one and included discussions around major parts of the body, distinguishing differences between people (by gender or body size for example) and changes associated with puberty and human and animal reproductive processes (Ministry of Education 1998). The major difference was that the 
old curriculum did not contain the "talking points" that gave teachers prompts and examples on how to approach certain subjects. Although the Globe and Mail pointed out that many of the curriculum elements - including the introduction of anal and vaginal intercourse- were already in place in other provinces (Hammer and Howlett 2010), and that the new curriculum was simply a minor tweak from the 1998 version, claims about the radical nature of the new Ontario HPE curriculum were repeated and perpetuated.

This isn't to say that those who supported the curriculum did not have a voice within the debates: several news stories featured parents or educators pointing out how much stray information youngsters were already getting about sexuality and how important it was to provide balanced information (Benzie and Rushowy 2010; Dunn 2010; Gordon 2010). Other journalists, such as Scott Thompson made reference to the evidence that "...reveals kids who get comprehensive [sexual] education do not have more sex or earlier sexual activity, and in many cases it actually decreased. Not to mention the benefits of learning safe sex" (2010), and in an opinion piece critical of the growing conservative backlash, sex therapist Sue McGarvie stated, "instead of what was actually proposed -a curriculum that gave age appropriate sexuality information- parents were scaremongered into thinking grade 1 students would get lessons on anal sex" (McGarvie 2010). These voices of support however, were not nearly as prevalent within the media as those of the opposition. Whether this was due to selective reporting on the part of the media, or simply an inability to mobilize official public support in such a short period of time ${ }^{4}$, those who supported the curriculum did not resonate as loudly in the

\footnotetext{
${ }^{4}$ Within the first 48 hours after McVety's press release, only the Elementary Teachers Federation of Ontario and the AIDS Committee of Ontario had responded officially in support of the curriculum.
} 
print media as those who opposed $i^{5}$. In this way, media representations effectively promoted a particular interpretation of the curriculum content and future outcomes.

As Cohen found in media reports of the Mods and Rockers incident, many who disapproved of the 2010 HPE curriculum used a blatantly violent rhetoric. For example, worried parent Yves Apel pointed to the idea that "imposing [curriculum] information on children..." has negative effects, and that "A six-year-old should be learning how to tie their shoes and playing with Barbies (and not, presumably, asking questions about what this part of Barbie does to that part of Ken)" (Apel 2010).

Here, the childhood icon of Barbie, and the idea of playing with dolls as a marker of innocence, is being juxtaposed with a language of vulnerability and harm in which children are being "violated by the promotion of [the HPE curriculum]" (Babbage 2010). Some referenced sexual knowledge as equivalent to physical harm, for instance, one concerned parent remarked --in an article which appeared in the Guelph Mercury on May 7-- "we are not obliged to meekly sacrifice our children to the stateist government that pander to the sexual libertinism running amok in our times" (Hamel 2010). Using such terms as "obliged", "meekly" and "pander", the author positions anyone who accepts the curriculum as victims of government control. Such statements effectively embellish the power of the State both in the curriculum debates and in the everyday lives of youth. In the words of Ekron Rushfeldt, Executive Director of Canada Family Action: “Ontario's new sex education curriculum for $3 \mathrm{rd}-7$ th graders is bordering on criminal. Canada

\footnotetext{
${ }^{5}$ After the curriculum was retracted, there was an enormous amount of back and forth discussion between supporters and opponents regarding both the curriculum content and the Liberal governments decision to "rethink" the sex education components. However, the majority of these debates only emerged after McGuinty announced that the sex education curriculum would not be put into place.
} 
prosecutes persons for corrupting minors with explicit sex. To cause confusion in a young child's mind... is evil and teachers should refuse to present this onerous material" (McVety 2010). In each of the preceding statements, discursive emphasis is placed on the dangerousness of sex education for the young child. To achieve this, the authors have relied on exaggeration and overestimation of the risks and harms (perhaps the most extreme is to link it with evil) associated with the implementation of the curriculum. By using words such as "corruption", "sacrifice" and "impose", opponents such as Ekron Rushfeldt exaggerated the negative consequences that would accompany the HPE curriculum, and successfully label anyone who supported the changes as evil, and a corrupter of innocence. It was through the media repetition of these sensationalized and highly stylized reports of opposition that much of this anxiety was mobilized. So much so that many opponents of the curriculum accused the Liberal government of "corrupting young minds with sexually explicit material" (Babbage 2010) and some parents claiming that the intent of the new curriculum was to promote homosexuality in youth. This misrepresentation and blatant distortion of the Liberal government's goal of inclusive and equitable education, was a large part of the strategy to defeat the HPE curriculum.

According to the proposed curriculum, discussions about homosexuality would begin in grade three, as part of a larger discussion around both visible and invisible differences among people. This included physical, mental and emotional disabilities, race and ethnicity, as well as the idea that some students may have same-sex parents. In an article in the Globe and Mail, McVety accused Dalton McGuinty of listening to special interest groups in the construction of the new curriculum. In particular, McVety suggested that former Education Minister Kathleen Wynn, who is openly gay, had 
influenced the curriculum, such that homosexuality and transgenderism would be promoted in schools (Hammer and Howlett 2010). Such claims exaggerate the role that any one person had in the development of the curriculum, and do not reflect that actual content of the HPE curriculum. Even so, concerned parents were alarmed by McVety's statement. Concerned parent Rahatoola Rujeedawa (2010) boldly stated, "sex education should be strictly confined to the area of male-female relationships. The responsibility of the educational system is to make responsible citizens of the children under its tutelage and not turn them into kinky predators". Such statements reflect a particularly adultcentric view of youth's sexual behavior and serves to reinforce the heternormative development of productive adult citizens. More, it reinforces the notion that homosexuals are both irresponsible and sexual predators.

\section{3-Prediction}

"Let this happen in any way, shape or form and it will come back to bite all of us in a big way" (Nigel Kettle 2010).

Using Cohen's (1972) media inventory, the proposition that youth sexual knowledge, resulting from exposure to the HPE curriculum, would be followed by more serious events and consequences was prevalent through the reporting of the HPE debates. Despite the fact that parent Nigel Kettle did not offer an example of how the HPE curriculum would "bite us all", a number of other concerned parents did. In particular, parents argued that presenting children and youth with sexual information would sexualize them at younger ages and create a cultural tolerance for earlier sexual activity. For instance, in the Hamilton Spectator, Mary Ellen Waschuk said: "In my opinion this is going to cause more teenaged pregnancies and more STI's (sexually transmitted 
infections). I really think that this has not been worked out properly. If this does come into place, I fear I will have to exempt my future kids from this program" (2010). Another parent said, "there are enough problems right now with teenage pregnancies and single mothers. The Education Department's goal should be to teach students about the dangers and consequences of irresponsible sex" (Rahmatoola Rujeedawa 2010). Taken together, these ideas speak to the dangers that would accompany youth sexual knowledge, regardless of the research that suggests kids who get comprehensive education do not have more sex or earlier sexual activity, and in many cases it actually decreases (see Bay-Cheng 2010; Kirby, Laris and Rolleri 2006; Morris 1994; Raymond 1994; Wyatt and Riederle 1994).

During the debates, concerned parents questioned whether "some of the talk will put ideas into the heads of young children who aren't ready for them" (D'Amato 2010), suggesting that some parents saw the HPE curriculum as a sort of instruction manual for diverse sexual acts and behaviors. Ekron Malcolm, Director of the Institute for Canadian Values pronounced that the new curriculum would "...end up infringing on their thought processes and their desires and ability to make correct choices" (Apel 2010). These allusions to "thought processes" and "ability to make correct choices" reflect socially conservative fears that introducing sexual information to children who are sexually immature, will negatively impact normal (read hetero) sexual development and could lead to apparently "devastating" social consequences such as the aforementioned unplanned teenage pregnancies and higher STI rates among youth.

Charles McVety went so far as to suggest that discussions around sexual diversity would create homosexuality or lead to transgenderism, "now, most adults do not question 
their gender identity. But we're now going to teach little Johnny to say, 'Well, I'm male on the outside but maybe I'm a girl on the inside" (Babbage 2010), playing on the parental fear that their children may grow up to be something other than heterosexual or having "normal" gender identities. For example, Cambridge mom, Patricia Murphy, suggested that "a girl who climbs trees and plays sports with boys will start worrying that she is transgendered- that she is really a boy in a girl's body" (D'Amato 2010). Here, we can see the effect of the exaggeration representations and overestimations in which some people come to see sexual knowledge as having a determining effect on gender identity.

\section{4- Symbolization}

"For some kids, it's too much too soon" said Vilia Milic, a Hamilton schoolteacher who taught for 36 years before retiring. "We're not letting kids be kids. We're rushing them. Whatever innocence is left will no longer be there ..." (Prete 2010).

Although those opposed to the HPE curriculum could be seen using Cohen's conceptualizations of a moral panic through exaggeration/distortion and prediction, no discourse was mobilized as loudly or repeated as often in media representations as that of symbolization. Numerous people voiced their disapproval and discomfort with presenting sexual information to children in elementary schools. In fact, I did not find a single article that opposed the curriculum that used the term "youth"," teenager" or "adolescent". This reflects an understanding among opponents to the curriculum, of the rhetorical currency of the term, "children" in which all of those from grade one to grade eight are cast as the same: differences in intellectual, social and emotional maturity are ignored in such a proposition. While in fact, the proposed curriculum was tailored to be delivered to students at age-appropriate times during their elementary career. By using the term "children" in all cases, the media led reaction to the curriculum was magnified 
and widened to negate the physiological, emotional and intellectual differences between five and fourteen year olds. In this way, opposition effectively used the media as a platform to emphasize the HPE content as corrupt and corrupting.

Of the 406 articles collected for this research, 314 of them made some reference to childhood innocence or purity ${ }^{6}$, suggesting that physical and emotional fragility is the one characteristic innate to children. Since sexual naivety is often conflated with popular conceptions of childhood innocence, sexual knowledge, then, is seen as harmful to those not ready for it. For instance, journalist Jeff Pearce declared "anybody with an ounce of common sense knows that the freedom and joy of pure innocence belongs inextricably to small children", and "...the vast majority of children who are not ready to be pushed into the world of adults" (2010). Although opposition pointed to potential issues such as teenage pregnancy, early experimentation and higher STI rates, the crux of the argument against the curriculum was whether the HPE was presenting too much (adult) information at too young an age.

During the HPE debates, there were some opponents who held an ideal that children be protected from sexual knowledge; however, they also expressed an understanding of the significant influence of media on children and therefore recognized the importance of providing accurate information to children in schools. Many pointed to the plethora of sexual images and increasing sexualization of children and youth as the primary reason that they need to be publicly educated about matters relating to sex and sexuality. As one person indicated, when "watching baseball means seeing commercials

\footnotetext{
${ }^{6}$ Although a methodical content analysis was not the goal of my research, this statistic is important for showing the ubiquity and repetition of the discourse around childhood innocence.
} 
for Viagra, youth television features same sex couples, magazines extol body-revealing fashion and the Internet allows access to a deep vein of explicit and often bizarre sexual behavior" (Humphrey 2010). Some theorists argue that adolescents are particularly vulnerable to sexual content in the media as they are in the middle of a developmental process where gender roles, sexual attitudes and sexual behaviors are being shaped. However they lack the cognitive skills to critically analyze messages from mainstream media and make rational decisions about possible future outcomes (Thompson 2010). Therefore sexual images have the potential to wreak havoc in the normative sexual script of young people.

According to Hall's recapitulation theory, youth must be either overtly or covertly controlled until they internalize the moral character necessary for adult citizenship (1904). Thus, notions of youth work symbolically as a moral boundary, not only "protecting" youth from the world of adults, but also regulating adult behaviour and protecting children from adult sexuality. Culturally, therefore, it is considered important to regulate the transmission of sexual knowledge available to youth, in order to preserve their own safety and innocence, and to redefine the boundaries of adult sexual life.

However, many critics of the Ontario proposals regarded the curriculum as a kind of capitulation to the current culture of sexualization. "There's no doubt that children are exposed to hostile sexual material more than we even dreamt of in our youth," said Charles McVety in an editorial by Jeff Pearce in the Windsor Star, "but that doesn't mean our teachers should be the exposers" (2010). For many, the HPE curriculum was simply perpetuating the early sexualization of children and youth and although some felt it was necessary to teach youth about topics relating to sex and sexuality, the age at which to do 
so was a source of contention. For instance, McVety suggested that, "these topics can be taught at the high school level, at the university level, when children can make up their minds" (Nguyen 2010). Such a position reinforces the view of sexual information as dangerous and children as sexually naïve. This raises questions about the sexual autonomy and agential capacities of young people. The common theme that emerged through media editorials and letters was one of corruption and exploitation in exposing youth to information that has "no relevancy to them at this point" (Nguyen 2010), and that "would have put adult issues on the backs of children" (Hamilton Community News 2010).

This discourse of corruption was prevalently represented through coverage of the role of Catholicism and the Catholic school board ${ }^{7}$. According to theorist Sandra Vergari (2000), the public education system bears special responsibility for preparing youth for adult life. Schools play an important role in not only acquiring knowledge and technical

\footnotetext{
${ }^{7}$ The role of the Catholic School Board in the HPE debates was transient at best. Prior to the debates in April and May 2010, it was widely accepted that the Catholic system had the right to interpret curriculum guidelines in a distinctive way, a right applied especially to sex education and religious education. The Ministry of Education had offered considerable funding to the Catholic school board to identify links between the HPE document and the 'Fully Alive' program that was part of the Catholic Family Life Curriculum (Rayside 2010) Members from the Institute for Catholic Education and the Catholic Association of Religious and Family life participated in each training session offered during the consultations and were seemingly on board with dovetailing the HPE content with Catholic ideologies. Even so, Ontario Premier Dalton McGuinty highlighted the issue of Catholic schooling in a debate during public question period, insisting that the new curriculum would apply to all students in publicly funded schools, including Catholic schools. In this, he failed to acknowledge the agreement particular to Catholic schools that they would be able to adapt the curriculum to their own needs. While it was quickly clarified that the Institute for Catholic Education had been involved in the development of the curriculum and that everyone involved in the process recognized that adaptations were available to the Catholic schools, the Premier's misstep challenged the trust that had been afforded to the school board by parents and religious educators.
} 
skills, but also in socializing students according to the norms and mores of society. The moral values expressed by the public schools can be interpreted as the expected values for all members of society (Benninga 1991; DeRoche and Williams 1998; Wynne and Ryan 1993). Concerned parents and Catholic educators, then, questioned why "children are being force-fed a secular, mechanistic, trivial view of sexuality that may well corrupt them for life" (Hamel 2010) and reinforced the idea that the sex education components would corrupt traditional Christian values, due to their alignment with secular ideologies. According to one opinion piece published in the Guelph Mercury:

sexual expression is seen as a gift from God that affects propagations, promotes human bonding between couples and gives appropriate pleasures. Indeed for many Christians, the way in which sexuality is expressed is vitally connected to their relationship with God, for the Bible is very clear that God's good gift is to be expressed only within certain guidelines" (Hamel 2010)

These guidelines, according to the Christian doctrine, involve heterosexual acts, between consenting and married adults, and see all other sexualities as falling away from traditional morality. Coupled with the belief that homosexuality is intrinsically sinful and that gay and lesbians often recruit children "to be gay" (Provenzo 1990; Skaggs 1996), the main goal of the Ministry of Education--to provide an equitable and inclusive education and see students of all diversities reflected in the curriculum--was increasingly considered threatening to both Christian values and heterosexuality. Although the Ministry of Education affirmed that it was value-neutral, members of the Catholic school board believed that the curriculum promulgated an alternative moral code and therefore ought not to be implemented in Catholic schools.

For many Catholics, the survival of conventional Christianity was of paramount importance as the secular view of sexual expression was: 
akin to relieving an urge or an itch... sex is kind of like belching, blowing your nose, or passing gas. It's just something the body has to do and it's not terribly significant in the short or long term scheme of things. So in the end, who you sleep with, or how you do the 'sleeping' is of no importance (Hamel 2010).

This idea, juxtaposed in the same article as the previous quote, presents secular sexuality (the HPE curriculum) as banal biological impulse that expresses human life as a series of unconscious impulses and unregulated desires. Based on this view, sexuality is considered a system of belief that, if introduced to children, threatens both individual and social decay. Sexual life is dangerous and corrupting and unless strictly regulated by morally sound Christian parents, bears no social value or moral value.

These concerns about childhood corruption were orchestrated through the use of highly stylized and stereotypical images of children. For instance, in an editorial response to the curriculum changes published in the Hamilton Community News (2010), one parent stated, "does this agenda need to start in grade 1, when children are learning to tie their shoes?'. Another parent questioned whether children should be learning information "about the same time they are learning to multiply 4 X 3" (McGarvie 2010). This strategy equates childhood with the modest intellectual capacities of young people, and creates room for wider discussion around the symbolic (both physical and emotional) characteristics of children and youth.

In Charles McVety's initial press release, he quotes Reverend Ekron Malcolm, Director of the Institute for Canadian Values when he states, "I believe this is a form of controlling the minds and desires of our young children who should not have to think about sex at such a delicate age" (2010). Editorial writer Yves Apel, contended that "...[no one] gets hurt by withdrawing this information... On the other hand, I can tell you who gets violated by the promotion of this topic- the vast majority of children do". The 
use of words like "delicate" and "violated", imply that children are fragile, vulnerable, frail and weak. Constructing them in this way, moral crusaders are more able to legitimize heavy-handed interventions into the lives of children who are seen to require such "protection".

Opponents also repeatedly used words such as "joy", "innocence", and "freedom" when referring to the symbolic state of childhood, suggesting that sexual knowledge would alter this state of being. Both linguistic techniques suggest that sexual knowledge is inimical to the utopic world of childhood-that is, that cultural definitions of childhood are premised on the absence of sexual knowledge. Reinforcing the pure and chaste child as one who has not been morally or symbolically violated by sexuality--by using overtly destructive language to describe one who has been or could be corrupted-- serves to reinforce popular conceptions of the child as being uncontaminated by the sexual representations that we associate with adulthood. This idea was also reinforced through a repetitive rhetoric around the protection of children. For opponents, childhood is a symbolic state of innocence, essential to the proper development of the child. According to some parents:

Growing up is confusing enough. We should not be hiding these issues, but we should not be forcing them onto our kids as part of regular curriculum. Some things may remain mysterious until they are much older. By imposing this information on our children, we are condoning behaviour that is outside children's sphere of interest, involvement, understanding, and maturity level. Let them have their innocence... The whole argument that we cannot shelter them and they will do it anyway is completely fabricated. Yes, we can shelter them, and it is our obligation to do so (Apel 2010).

Often in the debates, opponents pointed to the "confusion" that would be caused by exposure to sexual knowledge, and the responsibility that adults had in preventing this confusion. Here, child protection was entwined with parental responsibility; this neo- 
liberal form of self-governance points to the obligation of adults to protect and ensure children are kept naïve around sexual matters. In the media reports, the word "confusion" became synonymous with moral upheaval and childhood corruption. Since children are unable to govern themselves (by the very definition of popular constructions of the child as credulous and naive), the implication is that parents have a responsibility to prevent such "confusion". This conception however, further alienates youth from accessing information that might otherwise clarify their own confusion about sexual matters. Indeed, throughout all of the news articles I collected, not a single one was written by or responded to, by a youth, young person or student who would have been affected by the new HPE curriculum. This serves to reinforce the reponsibilization and parental subjugation of youth sexuality.

Those in opposition to the curriculum effectively framed the protection of children as an individual rather than institutional responsibility, by positioning "good parents" (those who opposed the curriculum) as virtuous citizens and the protectors of children. Note here that the construction of the vulnerable child also serves to construct the moral parent. For instance, journalist Jeff Pearce stated, "if good men and women fail to make a stand to protect the minds and hearts of our future, the youth, we will soon reap a whirlwind of destruction beyond imagination" (Pearce 2010). Here, "good men and women" is used to organize the HPE debates as a moral universe divided simplistically into good and evil, with opponents to the curriculum characterizing themselves, either implicitly or explicitly, as morally good. To prevent sexual knowledge and sexual activity too early meant preserving domestic life and thus social order. 


\section{5- Discussion}

Using Cohen's media inventory I have demonstrated how opposition to the curriculum effectively provoked a diffuse set of popular anxieties about the social development of young people, the dangers of sexual diversity and the role of the state in teaching morality and social responsibility. This chapter has described how the panic was mobilized along these themes, using specific linguistic and semiotic techniques and how print media become a platform in which to disseminate concerns over the curriculum content. However, the question remains as to why the panic was organized around the particular issue of sex education in the first place?

Moral panics only erupt during periods of rapid social change and anxiety, and the locus of the panic becomes a symbolic chalkboard in which potent anxiety is exorcized. Some theorists suggest that those things that we identify as a cultural risk are more about our own sociological constitution as a society than about the actual "thing, person or group" feared as risky. According to Douglas and Wildavsky (1982), the risks that we identify "out there" reveal as much about us-about our psychological traits, our cultural biases, our structures of perception, and our institutional affiliations- as they do about the hazards and contingencies in our environment. As such, the themes that emerged through HPE opposition in this research -namely the social and moral development of youth, the acceptance of sexual diversity and the role of the State in regulating youth- can be understood as symptoms of a more generalizable social anxiety that was projected onto the connection between youth and sex. These themes are indicative of a broader cultural anxiety that emanates out of the erosion of bounded age categories, the nuclear family/traditional gender roles and organized religion. 
Power \& Age

Concerns surrounding the social category of childhood resonated loudly in the HPE debates, expressing an unresolved tension about the age at which children become sexually and morally autonomous. Opponents effectively positioned all youth who would be affected by the new curriculum as children, successfully eliminating any developmental distinctions between broad ranges of children and youth. As such, the opposition painted children as a uniform social group who were seen as antithetical with sex. Although discourses on childhood have exploded in the $20^{\text {th }}$ century, there is no consensus among these on definitions of the child. Although traditionally, the physical marker of age was used to determine the boundaries between children, youth and adults, this inner etiology has been challenged by socialization theorists who suggest that more fluid characteristics, such as sexual maturity and innocence, and life experiences are the modern markers between social categories.

The discourse of childhood innocence, through sexual naiveté, however, has remained salient since the inception of "the child" in the late nineteenth century. Today, the complete disengagement of children and sex can be seen through social and judicial channels, such as age of consent legislation (which regulates the age at which children can become sexual subjects), sexual exploitation laws (which mandates the protection of children from adult sexual encounters) and the vilification and public outrage relating to paedophiles (indicative of a potent cultural anger that is expressed for people who physically and symbolically destroy the sexual innocence associated with children). In this context, it is particularly intriguing to see how "the archetype of the child is sustained in language and in the discourses of the professions, the institutions and the 
specialisms... and serves to patrol the boundaries marked out around childhood as a social status" (Egan and Hawkes 2008:194). More often than not, the child is understood as simply a character who exists in the realm of a structured adult world as opposed to an active agent. Children, then, "often become the focus of innumerable projects that purport to safeguard it from physical, sexual and moral danger to ensure its 'normal' development" (196). More than age, legal or religious discourse, childhood has been institutionalized as a category of risk.

In addition to deploying a framework of innocence and fragility, opponents also posited young people as potentially sexually dangerous. The specific idea of adolescence, defined as a period between childhood and adulthood, was outlined by G. Stanley Hall in his 1904 book Adolescence, which provides the first 20th century discussion of the relationship between adolescence and distinctive patterns of behaviour among young people. Problem behaviour among youth was seen to result from chemically based bodily changes ordinary to the biological transition from child to adulthood, with social conditions seen as aggravating this condition. Hall thus placed great emphasis upon adolescence as being a time of emotional "storm and stress", suggesting that the concept of adolescence relates to the psychological problems associated with the transition from childhood to adulthood in modern societies - problems that only arise in these types of society because small-scale, non-industrialized societies do not develop a transition period between childhood and adulthood.

Throughout my analysis of the HPE debates, opposition routinely made reference to the fact that teaching young people about sex and sexuality would cause both a "whirlwind of destruction" (Pearce 2010), in the form of teenage pregnancies and STIs, 
and would sexualize them by destroy the important symbolic boundaries demarcating childhood from the adult world. Becoming sexual therefore is not seen as a routine part of growing up, but something to be hedged around with cautions, warning and prohibitions (Jackson and Scott 2004:3).

However, this becomes increasingly difficult, as one of the key contemporary challenges facing youth today is the increasing uncertainty that characterizes modern life. Since the start of the 21 st century, sociologists have been suggesting that with the decline of many traditional boundary-setting social institutions (such as organized religion and the nuclear family) self-identity has become much more "reflexive" or "liquid". This means that the guidelines - the social rules and structures - that we once looked to tell us who we were and who we should be are no longer as resilient and influential. Modern peoples are more reflexive, and likely to adopt views, values, behaviours and beliefs from a wide range of options, than to follow along traditional pathways established by their parents. Sociologist Anthony Giddens (1984) argues that this reflexivity occurs with no broad-based moral structure to guide it. For young people today, there are abundant choices on "who and how to be"- the world is full of apparently endless opportunities.

"As the liberal state has shifted its concept of citizenship from one based on rights to one based on responsibilities, even youth are expected to enter into citizenship by making choices that will lead to a successful future as an independent citizen consumer" (Lehr 2008:209). Faced with a proliferation of choice young people can now decide themselves between a plethora of different lifestyles, subcultures and identities. With these opportunities, also comes an increased risk for young people in the form of guilt or blame if they end up on the margins of society as a result of these choices (210). This 
sends a mixed message- on the one hand; youth are seen as a dependent group, incapable of making their own choices (which can often result in punishment) and on the other hand, should not be dependent on parents as this is seen to foster laziness, dependency and social incompetence.

Importantly, taboos regarding young people and sex also reflect our fears that children and adolescents may be easily exploited and victimized, a theme that was prevalent within the HPE debates. In defending the concept that children and young people need protection from sexual exploitation and sexualization, Western society has become invested in the idea that we cannot allow youth any sexual agency at all. Therefore, when those in opposition to the curriculum created a false link between sexual knowledge (the HPE curriculum) and early sexual activity, they highlighted a potent cultural contradiction that has existed as long as the category of "youth" itself. Young people are seen as lacking the maturity to make good sexual decisions and are also viewed as vulnerable to sexual exploitation: together, these perspectives create a contradictory system of power and control, which creates a persistent cultural unease around youth sexuality.

However, the HPE curriculum debates were not simply about the antinomous relationship between youth and sex. The opposition effectively framed the debate around institutions and moral codes that have historically been the foundations of western society, namely the family and the church. The panic surrounding the HPE curriculum emerged because of a broader social anxiety felt around changing forms of social and moral regulation. 


\section{Family}

For HPE opponents, it was not simply an issue of sexual knowledge and agency that was deemed harmful, but what this deviation from traditional morality meant for social advancement. Central to the sex education debate was an attempt to preserve patriarchy and to privilege men's over women's rights as well as parental over children's rights (Bendroth 1993; Hawley 1994; Howland 1997; Marty and Appleby 1999; Riesebrodt 1993). Historically, youth were managed by institutions that were moderated by the status granted to heteronormative adulthood (Egan and Hawkes 2009:59), such as the nuclear

family. The family is the arena around which most people organize their sexual needs and identities. In fact, sexual socialization has been perhaps the most significant function of the family. However, the past several decades have seen an increase in the visibility and acceptance of non-traditional forms of family structure, which include common law relationships, cohabitation, single parent families and homosexual relationships. Such relationships are deemed to be non-conventional because they do not reflect the demographic characteristics that social scientists have largely focused on when typically discussing family structures (Bauer 2004).

The visibility of these families has produced numerous anxieties, around the changing patterns within the private realm: as kinship and family patterns change, so do attitudes and beliefs about sex and gender. The opposition to the HPE curriculum drew on fears surrounding these shifting patterns, suggesting that homosexuality and transgenderism were foundational to the curriculum. In the debate, homosexuality is portrayed as a threat to Western civilization, Christian salvation and in particular, to the safety and well-being of innocent school children. Thus, any policy or program perceived 
as being remotely pro-gay is considered a conspiracy to recruit children to alternative

lifestyles. As the HPE debates showed, such a perspective reflects a level of paranoia, capable of mobilizing parents and concerned citizens toward protecting "our very way of life". Yet the incendiary language provides an important theoretical key. As historian Richard Hofstadter (1963) explains,

The paranoid spokesmen sees the gate of this conspiracy in apocalyptic terms- he traffics in births and deaths of whole world, whole political orders, whole systems of values. He is always manning the barricades of civilization. He constantly lives at a turning point; it is now or ever in organizing resistance to conspiracy, time is forever running out (29-30).

It is this deliberate constructed spectacle of fear (Edelman 1988) that gave the opposition potency regarding the politics of the HPE debate. However, it also gave rise to an interesting paradox: although there is a seemingly increased tolerance for alternative lifestyles within social modernity, Jackson and Scott (2004) argue that this acceptance still revolves around the heterosexualization of such a relationships. This creates a cultural collision, in which actual equality is overridden by an implicit heterocentrism: gay and lesbian relationships are more socially acceptable if they mimic the hetero-normif they are long-term, monogamous and stable, and if they buy into the dominant family values (237). Gender relations are central in this model so that society can "proceed towards its 'normative' monogamous productive end" (Egan and Hawkes 2008:356) So while alternative family forms may be tolerated, heterosexuality is institutionalized as a sets of values and practices that should underlie all family formations.

By linking the HPE curriculum with anticipation and prediction of future behaviours and lifestyles, opponents illuminated a broader social anxiety felt about changing family patterns and the confrontation to heterosexuality and traditional gender 
roles. The current sex education debate, while concerned with trying to prevent "the corruption of the child", was as much, if not more about trying to preserve or reclaim the patriarchal, nuclear, heterosexual, Christian family. With the displacement of the nuclear family as the only acceptable family form (and thus "normal" gender relations) and the increased visibility of alternative households, the private sphere becomes increasingly uncertain. This instability has proven to be too much for some members of contemporary society and sexually active youth have become a symbolic surface upon which challenges to traditional life get animated.

\section{The Church}

It is recognized that there are many tensions between conservative religiosity and more secular perspectives on sex and gender, within and outside the Judaeo-Christian tradition. The HPE discussions around child and youth sexual agency and sexual knowledge, existed as part of a larger debate around the ownership of moral issues, the capabilities of parents to cope with modern circumstances, the incursion of the state into the private realm and the perceived wane of religious influence (Adams 1997:112). According to Christian doctrine, a well-adjusted (and morally sound) individual would wait for marriage to engage in sexual activity, so supplying youth with sexual information was simply unnecessary (McKay 1998:66). Presumably, keeping sexual information from youth would work in conjunction with restrictive Christian norms to uphold the virtue of premarital virginity, keeping children and youth sexually innocent.

Given the role of the school, members of the religious right were deeply concerned regarding their possible immoral influences. Although some saw organized religion as providing a moral counterpoint to the scientific teaching that students would be presented 
with in schools, other believed that sex education should be kept in the home. Previous to the discursive explosion of the $19^{\text {th }}$ century, Canonical law, the Christian pastoral and civil law determined the division between the licit and the illicit; the moral and immoral were separated and enforced by religious and community organizations (Kinsman 1994:166). However, one of the most critical shifts over the last hundred years has been a move to an increasingly secular society, replacing moral regulation by the church. This has created a cultural anxiety around moral issues, and the introduction of sexual matters into a publicly funded classroom put the school in direct competition with the home and church as the primary site of young people's sexual (and therefore, moral) development (Adams 1997:114). For the HPE opposition, to make this shift was to acknowledge that those institutions were no longer capable of fulfilling certain moral responsibilities, as they had done historically. Numerous articles reference the McGuinty government as being overly intrusive, and "infringing on the rights of parents" (Randall 2010). Ottawa Archbishop Terrence Prendergast pronounced that "governments are there not to dictate to us, but to be responsive to our needs and to coordinate matters in our society for the well-being of all. They're not there to govern every aspect of our life" (Randall).

Historically, the Church has been an institution that gave rise to a shared sense of identity and group cohesion and was seen as a general antidote to moral decline (Adams 1997:112). To recognize its diminished importance to the majority of people would be to acknowledge the uncertain and ambiguous nature of life in the west. Therefore, the HPE debate became a microcosm for a larger cultural apprehension around the social and moral climate, characteristic of modernity. 


\section{6- Concluding Remarks}

Throughout the HPE debates, opponents continuously framed youth as a symbol of innocence, vulnerability and goodness and used the media as a platform in which to perpetuate and reproduce these ideas. They did this by using the word "child" as opposed to youth, and repeatedly referenced popular notions of vulnerability and fragility suggesting that children are a group in need of adult protection. Sexual matters were consistently represented as for adults-only: introducing these topics to children would cause undue pain, confusion and harm. However, it has become increasingly difficult to shelter children and youth, in a culture that is saturated with sexual imagery and ideologies. Therefore, capitalizing on cultural norms in which children depend singularly on parents and not social institutions or government, opponents framed the debates within an exaggerated discourse of danger in which "good parents" would have a responsibility to protect children from the sexualization and future dangers that they saw accompanying the HPE curriculum.

These ideas, in combination with the exaggerated and distorted rhetoric and predictive elements of the HPE consequences, produced a media orchestrated moral panic in April/May 2010. Charles McVety's initial, press release, in response to the Hamilton Spectator article, was laden with an intensely hyperbolic vocabulary, which framed the debate, and was subsequently repeated in the media with emphasis on certain key points. In particular, how the curriculum was to provide instructions on the pleasures of masturbation, vaginal lubrication and anal intercourse. Specific teacher prompts and examples were taken out of context. The ensuing media frenzy was laden with 
homophobic quotes and opposition repeatedly referenced the pitfalls of youth sexual activity and negative future consequences of this behaviour.

However, according to Cras Critcher (2006) in a moral panic, the meaning of the act and the act itself are detached from one another, and we become oriented towards the symbolic rather than the real problem. Thus the panic surrounding the HPE debates, was not about youth and sex, but revolved around core tensions about the state of social modernity and wider structures of social life. In discerning what discourses brought about the moral panic, I was effectively able to illuminate a deeper cultural angst --felt by opposition-- that has accompanied the decline of historic bounded age categories, the traditional nuclear family and organized religion. In the following chapter, I will examine these declinations alongside more contemporary structural reasons for the HPE panic, such as the pervasive sexualization of youth and the intensification of attempts by newspapers to attract readers by printing provocative stories. In doing so, I will elucidate a more holistic contextual understanding of the conditions that made the HPE panic possible. 


\section{Chapter 5- Conclusion}

It is widely accepted that late modern societies are becoming more liberal and open about issues relating to sex and sexuality (Jackson and Scott 2004). However, this has given rise to a number of associated anxieties particular to the ways in which sex acts and relations are socially ordered. In this paper, I have explored these tensions by examining the HPE curriculum debates as a particular instance of a media facilitated moral panic in order to illuminate the wider social anxieties that have emerged within modernity,

namely, the decline of the nuclear family, organized religion and traditional gender roles.

Moral panic is such a well-established term, both in academic and everyday vocabulary, that it is surprising to recall that it has only become widely used since the work of Stanley Cohen (1972) in the early 1970's in his work on youth subcultures. Using the conceptual tools that Cohen has provided through his analysis of the Mods and Rockers, it is easy to see that a panic emerged in relation to the HPE curriculum. Indeed, by using Cohen's media inventory, I have showed how opponents of the HPE curriculum framed the debate, and how mainstream print media disseminated this frame in April and May 2010. By repeating the most controversial issues in the curriculum (namely homosexuality, gender identity, oral and anal sex) and using language that triggered a broad social anxiety around children's access to sexual knowledge, the curriculum was effectively retracted from being implemented in elementary schools. Some suggested the government was indoctrinating the "young minds of tomorrow" by promoting and encouraging unconventional relationships and gender identities (namely homosexuality and transgenderism). The opposition to the curriculum repeatedly made reference to the future threat to the social order posed by the HPE curriculum, and relied on symbolic 
images of childhood innocence to successfully eliminate the sex education components. However as I have also established, the panic surrounding the curriculum had larger social roots. Although McVety's initial press release was designed to mobilize parents and concerned citizens to join the battle against the HPE curriculum, the fight was not simply about youth sex and the Ontario curriculum.

According to the moral panic literature, the ceremonial clash between a deviant "outgroup" and the rest of society results in the clarification of normative boundary lines. This demonstrates that there is a limit to the amount of diversity that a society can handle (Goode and Ben-Yehuda 1994). Thus the core tensions that became prevalent in my analysis of the HPE debates -namely the social and moral development of youth, the acceptance of sexual diversity and the role of the state in regulating youth, articulate certain challenges to otherwise traditional social institutions, most notably the nuclear family and the Church. These challenges also extend to social identities and identity categories, such as gender, and age. The panic then, serves to re-align institutional interests within social modernity.

Recall that Foucault's (1978) critique of the repressive hypothesis and perverse implantation has left sexual restrictions under the purview of scientific discourse, resulting in the "incorporation of perversions" and the "specification of individuals" (4243). According to this model, sexual proclivities constitute not just the acts of the body, but the key to unlocking one's character and therefore the most essential element in forming the basic core of one's identity.

According to Foucault, sex defines everyday life, and as I discussed in Chapter Three, sexuality only exists through social forms and organization, "far from being the 
most natural element in social life, the most resistant to cultural moulding, it is perhaps the most susceptible to organization" (Weeks 1986:18). As such, for opponents, when the influence of institutions that have traditionally been relied on to shape the organization of the erotic, -such as the family and the Church- decline, so too, does our sense of selfhood. It is this move away from religion and community organization (to that of science and rational thought) as a way of constructing sexual code that opponents of the HPE curriculum condemned throughout the moral panic.

However, there are also more contemporary reasons for why the moral panic erupted around the HPE curriculum. For example, throughout my analysis, I showed how the dominant oppositional discourse was constructed around the innocence and incompetence of childhood and youth and the need for their protection. However, given the media's obsession with the sexualization of youth culture and the ambiguity that surrounds the social boundaries between children and youth, through popular depictions of sexualized children, the construction of a sexual world in which children are, as an ideal, "asexual" no longer applies. Without clear sexual boundaries demarcating social categories of age, we are unable to know who "we" are (adults) if we can no longer determine who we are not (children or youth), thus the identity model of sexuality, characteristic of Foucault falls apart when dealing with discourses of youth sexuality. On one hand, sexuality is seen as an expression of adulthood, so that any positive sexual agency or independence on the part of youth is circumscribed (Lehr 2008). At the same time, the physical and symbolic make-up of the child has been translated into mainstream images as sexually and materially alluring through the increasing sexualization of children and youth in mainstream media. For instance, a recent study of ideal physical 
desirability using a computer program called FacePrints, found that "the ideal 25 -year-old woman... had a 14-year old's abundant lips and an 11-year-olds delicate jaw" (Kincaid 1998:18). We are told to look like children if we can, as long as we can, and to pine for that look in order to be sexually alluring. Cultural rhetoric insists, more than ever, on the innocence of children; however, it is that very innocence that has become highly eroticized in fashion, television and advertising.

Children's sexual vulnerability has become one of their most prominent characteristics, however the ways in which this has become commodified in modernity last led to a potent cultural angst around youth and sex. Opponents of the HPE curriculum used this fear in their campaign to retract the curriculum by routinely referencing the content in the curriculum as corrupt and corrupting. The emphasis here is that social control must be deployed at the level of individual consciousness, through which "good" citizenship is demonstrated through cautionary practises and the subjective regulation of the risk of children and youth to sexual matters. Although the sexualized child/youth is alluring and sexualization is an effective consumer practise, it is only effective if the child who is sexualized is not one's own, due to the dangers associated with sex. Opponents preyed on the anxieties surrounding the sexualization of "our" children, by linking the HPE curriculum with sexual thoughts, behaviors and actions.

This antinomous nature of sexual attitudes - to regulate and protect youth sexuality without allowing youth access to information about youth sexuality, in an era when sexual images of youth are inescapable, has created the conditions ripe for a moral panic to emerge. The anxiety expressed about sexually knowledgeable youth is strongly connected to the anxieties about the fragility of moral bonds in multiple aspects of social 
life (family, sexuality, gender) amid a cultural of ubiquitous sexualization. This creates room for a discourse characterizing youth as a group in need of management to prevent a future threat to the broader social order and to allow ordinary citizens to re-establish solid identities that have been lost with the decline in traditional morals and institutions. Youth, then, have become a symbolic device, which the threat of sex gets transposed.

As I have shown, the linguistic strategies used by the opposition were characterized by various contradictions and discrepancies around the symbolic construction of children and youth (and their relationship with sex), which had implications for how broader moral bonds are understood. Moreover, social unease about the shifting role of the state in social governance was highlighted during the debates. With the decline in the nuclear family and the Church, once ideal models for heternormativity and patriarchal values, a climate of institutionalized uncertainty has emerged. This presents precarious challenges to traditional gender expectations and a "normative" model of sexuality and it is this free-floating anxiety that has created the need for a moral panic around youth sex. It is only through the symbolic "folk-devil" of the sexual youth, that normative boundaries can be identified and identity can be reestablished.

\section{$\underline{5.1-\text { Sensational Media }}$}

There is also a structural concern, unique to this day and age that played a role in the emergence of the panic around the HPE curriculum. According to Cohen (1972), the role of the mass media is paramount in the development of a moral panic, and as I have shown, the news media played a large, if not facilitating role in the moral panic surrounding the HPE curriculum. However, news media has long been a victim of 
declining circulation and are currently undergoing a desperate attempt to extend their readership. Due to the advent of new technologies, such as the Internet, readers can now get information around the clock, for free, and therefore the need for print media is becoming obsolete (Norris 2000). Trying to find a kind of newspaper story that will appeal to the public is one of the obvious ways to reverse the decline in readership and is the feature of the press in many advanced countries.

One of the ways in which this has been done is an increase in the prevalence of sensational, prurience and trivial stories- shoddy reporting and the devaluation of the news agenda in the interest of entertainment, ratings and readers; a trend referred to a "tabloidization" of mainstream media (see Sparks and Tulloch 2000; Zelizer 2000 for further reading). Indeed, Newsweek concluded that "sizzle trumps substance" and in North American media, "news, public affairs and history are morphing into entertainment" (Alter 1999:24).

The type of newspaper that exists is the type that has survived under the conditions of modern life. The men who may be said to have made the modern newspaper... are the men who have discovered the kind of paper that men and would read and who had the courage to publish it" (Robert E. Park 1923:8).

Although this drive towards sensationalism is justified by reference to the decline in the market for news and the need to develop new kinds of news that can reverse that trend, it also created the cultural conditions for moral panic "events" to flourish. The claims made in the initial stages of the HPE panic generated a large amount of media activity and were therefore perpetuated by newspapers in the interest of readership. The media recognized and seized an ideal opportunity to continuously cover an issue that personally affects a large audience and involves harms against children, a group which has been referred to as "sentimentally priceless" (Zelizer 2000). Paradoxically, although this tactic may have 
created high interest among viewers and ultimately a higher readership base for newspapers, it resulted in the dissemination of false and misleading information that played on social fears and anxieties around sexualization, corruption and moral decline. Although there is an intensification of attempts to attract readership, during the HPE debates, this media desperatism exacerbated oppositional concern and regrettably left a large portion of Ontario's youth population without up-to-date sex education.

\section{2- Where Do We Go From Here?}

The discourse analysis performed herein demonstrates a set of contradictions that stand at the core of the debate of who we are as sexual subjects and citizens, within a climate of pervasive sexualization and desperate media attempts to attract readers. Using the dominant themes emerging from the media representations of the debate, I have demonstrated the discursive mechanics behind a widely felt fear.

There is a rich literature on moral/sex panics, social modernity and youth sexuality; to this body of literature this thesis contributes a view of the particular techniques employed during a sex panic in relation to a school curriculum. Through my analysis, I have identified the discursive strategies used to capitulate the curriculum in 2010 and have illuminated the particular "hot spot" issues given special attention during the debates, which had special resonance throughout two months of media coverage. By using the (sexual) constructionist framework provided by Foucault (1972), I have provided valuable empirical evidence to the particular sites of crisis -namely age, agency and institutionalized morality. Becoming familiar with the strategic mechanics of the 
opposition, is one way in which to undermine the panic and return to reasonable, informed and accurate discussions about the topic.

While I am making an intervention into debates on social change and sexuality, I have raised more issues that I am able to resolve. It seems the Ministry of Education was not flawed in how they chose to review and redesign a new HPE curriculum; as it was extensively consulted on, had approvals from teachers, students and parents and even had the Catholic school board in agreement on the well-researched and necessary changes. It was only a minor linguistic upgrade from the current 1998 curriculum, and prior to McVety's press release, there had been no mobilized public opposition to its content.

The HPE policy makers likely knew that sex education was always controversial and put parents and State in direct competition with one another; however, they were likely lulled into a false sense of security because of the widespread agreement among educators, academics and social service providers that the directions of the new curriculum were age-appropriate and long overdue (Rayside 2010). They underestimated the strength of the opposition and the powerful (and desperate) role of the media in circulating "newsworthy" information, so through the use of fear based tactics and the consistent exaggerated reporting of the issues by Canadian print media, opponents effectively dissuaded the Liberal government from implementing policy.

Cohen's (1972) work on moral panics was more clearly focused on the social and media reaction rather than the actual behavior in question, therefore one solution to this moral panic may lie in the very apparatus that perpetuated the HPE panic in the first place. Recall that the new HPE curriculum was placed on the website of the Ministry of 
Education and a memorandum was sent to school boards announcing its release. However the majority of parents of school-aged children were given no notice about the new curriculum, and therefore learned about it from the media reaction to McVety's press release. People often use the knowledge that they obtain from media to construct an image of the world (Surette 1992), therefore by distorting reality through focusing disproportionately on McVety's claims, the common viewer was made to believe that children really were learning about anal sex, vaginal lubrication and masturbation as part of the main curriculum content.

The public rarely has enough information independently on many issues, and are therefore at the mercy of media, not only for information, but also for interpretation (Graber 1980). How the popular media uses language to represent the social world has much to do with how the world is understood. However, due to the trend of attracting readers with provocative and sensational stories, the repeated references to exaggerated and distorted material was the initial point of contact for most parents and while some of the media coverage included reasoned response from defenders of the curriculum, the immediate profile given to the opposition and their framing of the curriculum as "controversial" inflamed early responses. There was no communication strategy about the HPE curriculum from the Liberal government or Ministry of Education, until after opponents framed it.

This strategy was effective, and relied on the idea that the media is the principal dominant mode of communication and generation of meaning in modern society. It is extremely difficult for the general public to compare media representations with direct 
experiences, and most parents, or journalists did not have the time or energy to comb through the 200 page. HPE curriculum document. Therefore McVety's interpretation and compelling narrative of corruption influenced public perception of the issue.

Print media I propose, could have been used in a reciprocal fashion. Had the Ministry of Education disseminated the "real" curriculum content in the same way that McVety's press release disseminated misleading information, the hyperbolic rhetoric that became characteristic of the debates could have been negated. Although the HPE curriculum document is dense, and time consuming to peruse, the Ministry could easily sum up the goals and changes in an accessible format and disseminate such a document to the parents of school aged youth, or through media press releases. In this way, controversial references to homosexuality, oral/anal sex and masturbation would be discussed in their proper context and citizens would not learn about curriculum content from editorial and opinion articles.

Including specific examples of "teacher prompts" and being made aware of the motivations behind the pedagogical practises and contemporary redesign included in the HPE curriculum is the first step in eliminating the inflamed response characteristic of the 2010 HPE debates. It is often too easy for individuals to get caught up in the most pressing, most highlighted issues and constructs, and demand "knee-jerk" reactions without careful consideration of the current situation, especially during times of moral and institutional uncertainty. However, by sculpting the initial communicative in such a way that the mass media disseminated contextualized and proper rhetoric, the sensationalism 
and concern that became characteristic of the HPE panic would likely be significantly decreased.

This isn't to say that all opposition would be extinguished with this strategy. As examined in the work of Foucault (1978) sexuality is an area imbued with monumental social significance, and as such, the battle over sex education has become a "clash over the shape and direction of society itself' (McKay 1998:13). While some of the conflicts around sex education appear irresolvable, the moral panic that ensued over the Ontario HPE curriculum was in large part a product of fear, hysteria and paranoia facilitated by Canadian print media in order to attract readers. Using the media to disseminate contextualized and correct information would significantly diminish the role it has in producing moral panics, creating room for more knowledgeable citizen subjects, less inclined to panic around "talking points" and "age-appropriate lessons". 


\section{Appendix A:}

\section{Healthy Living Summary: Key Topics. Proposed Health and Physical Education Curriculum, Grades 1-8.}

\section{HEALTHY LIVING LEARNING SUMMARY: KEY TOPIC**}

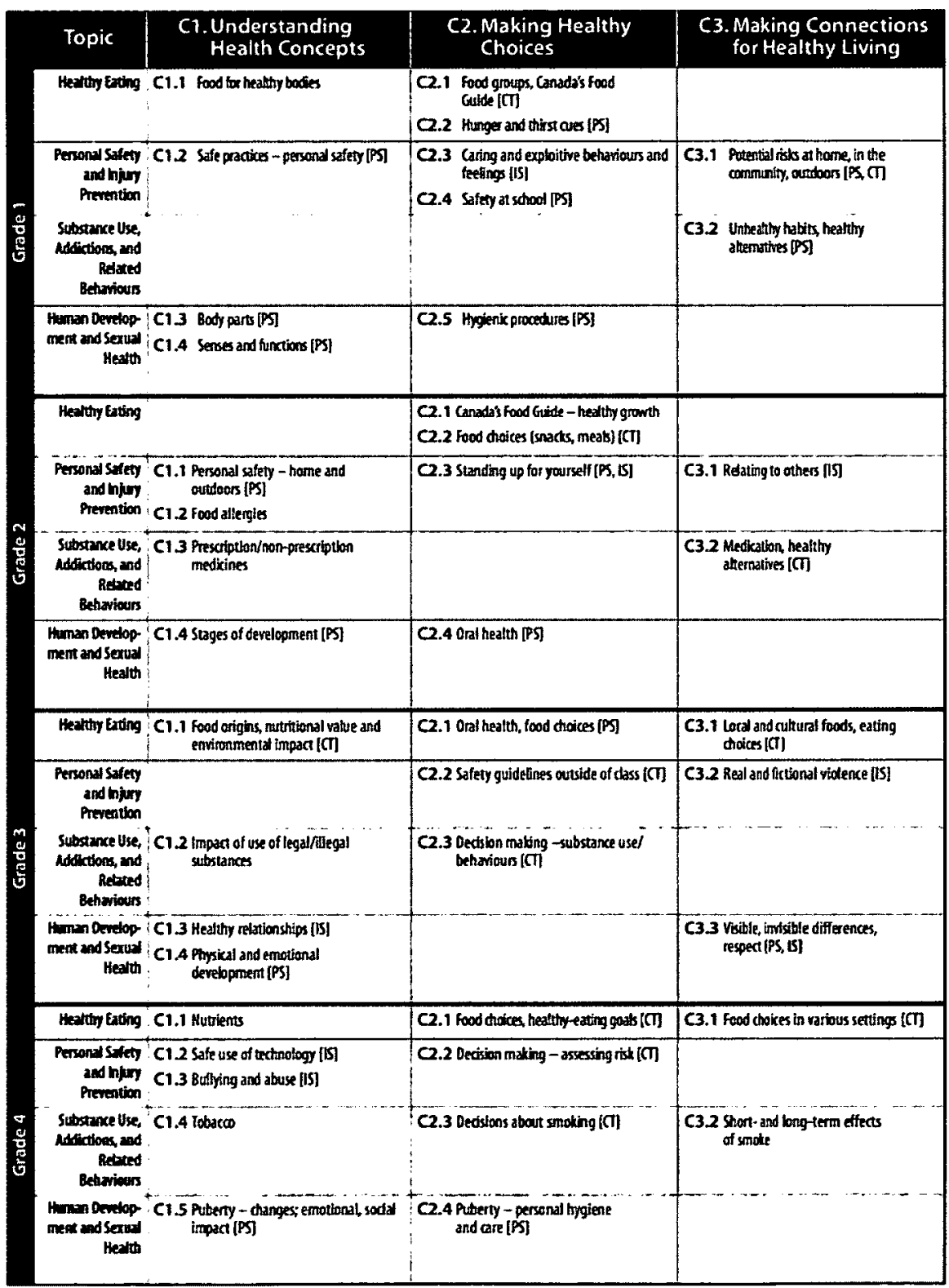




\begin{tabular}{|c|c|c|c|}
\hline Topic & $\begin{array}{l}\text { C1. Understanding } \\
\text { Health Concepts }\end{array}$ & $\begin{array}{l}\text { C2. Making Healthy } \\
\text { Choices }\end{array}$ & $\begin{array}{l}\text { C3. Making Connections } \\
\text { for Healthy Living }\end{array}$ \\
\hline Healkty Gring & & C2.1 Hurrition fares ables, food labds (m) & C.1 Medis influences - tood drokes [T] \\
\hline 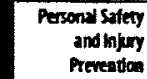 & $\begin{array}{l}\text { C1.1 Supports - injuy prevention } \\
\text { emergenxies, bullying violecose (PS) }\end{array}$ & $\begin{array}{l}\text { C2.2 Strategies - theast to personal sefety } \\
{[\mathbb{P S}, 15, \mathrm{~T}]}\end{array}$ & C3.2 Arcions, seff-concept (PS, IS] \\
\hline 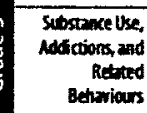 & $\begin{array}{l}\text { C1.2 Shon- and long-tem effects of } \\
\text { acohol use }\end{array}$ & $\begin{array}{l}\text { C2.3 Reficad stills - akobol use and other } \\
\text { behaviours is] }\end{array}$ & $\begin{array}{l}\text { C3.3 Devision to dink alcohol } \\
\text { influences }[\mathrm{a}]\end{array}$ \\
\hline $\begin{array}{l}\text { Human Derelop } \\
\text { ment and Sexast } \\
\text { Health }\end{array}$ & $\begin{array}{l}\text { C1.3 Reproductive sytem [PS] } \\
\text { C1.4 Menstruation, spermatogenesls }\end{array}$ & $\begin{array}{l}\text { C2.4 Emotional, interpersonal stresses - } \\
\text { puberty [PS] }\end{array}$ & \\
\hline Healthy bating & & $\begin{array}{l}C 2.1 \text { lnfivences on healthy eating }[\mathrm{CT}] \\
\mathrm{C} .2 \text { tating wes and guidel ines }[\mathrm{PS}]\end{array}$ & $\begin{array}{l}\text { C.1. Beneffis of hedhlyy eating/active } \\
\text { [ming [T] }\end{array}$ \\
\hline $\begin{array}{l}\text { Personal Salety } \\
\text { and lajury } \\
\text { Prevention }\end{array}$ & & $\begin{array}{l}\text { C2.3 Safe and positive social interaction, } \\
\text { confike management }(\mathrm{PS}, \mathrm{BS})\end{array}$ & 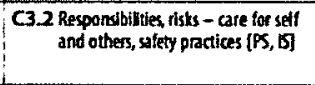 \\
\hline $\begin{array}{l}\text { Scbibtance Use, } \\
\text { Aoditcions, ind } \\
\text { Retated } \\
\text { Betavious }\end{array}$ & $\begin{array}{l}\text { C1.1 Effects of cannubis, illiait driys } \\
\text { C1.2 Supports - substance use, adfikctive } \\
\text { behaviburs }\end{array}$ & 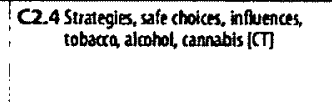 & \\
\hline 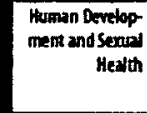 & C1.3 Developinemt of sel-concept (PS) & 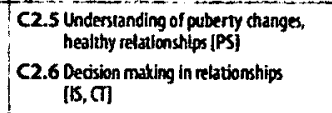 & 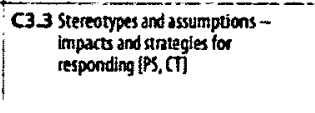 \\
\hline Heatdy Eating & & $\begin{array}{l}\text { C2.1 Food thoices and hedth } \\
\text { problems ICT }\end{array}$ & $\begin{array}{l}\text { C3.1 Healthy eating practices and } \\
\text { routines }\end{array}$ \\
\hline $\begin{array}{l}\text { Personal Satiery } \\
\text { and injury } \\
\text { Prevention }\end{array}$ & C1.1 Benefits and dangers - iectnology & $\begin{array}{l}\text { C2.21mpact - bullying/haxassment } \\
{[\mathrm{BS}, \mathrm{TT}]}\end{array}$ & \\
\hline $\begin{array}{r}\text { Sebstance use, } \\
\text { Mddetions, and } \\
\text { Retated } \\
\text { Betariours }\end{array}$ & $\begin{array}{l}\text { C1.2 Mential healten, substances, } \\
\text { support [PS] }\end{array}$ & C2.3 Bocy inage, subscance use lPS, Cn] & $\begin{array}{l}\text { C3.2 molicatlons of sublance use and } \\
\text { addectoons (m) }\end{array}$ \\
\hline $\begin{array}{l}\text { hemens Develop } \\
\text { ment and Senual } \\
\text { Hedth }\end{array}$ & 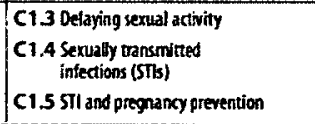 & $\begin{array}{l}\text { C2.4 Senual health und dedsion } \\
\text { maling [ [Sy] }\end{array}$ & $\begin{array}{l}\text { C3.3 Retationship changes at pubery } \\
\text { [IS, (C] }\end{array}$ \\
\hline Mealthy Exting & C1.1 Nutrients & C2.1 Food chaces - aitertas [O] & C3.1 Promming headhy exing [T] \\
\hline $\begin{array}{l}\text { Persentisifty } \\
\text { and injuy } \\
\text { Prevertion }\end{array}$ & (C1.2 Reduchng nist of injuries, death (I) & $\begin{array}{l}\text { C2.2 Assessing siturtions for potential } \\
\vdots \\
\text { danger [T] }\end{array}$ & $\begin{array}{l}0.2 \text { mppac of rident beharlours; } \\
\text { suppors }\{(\pi)\end{array}$ \\
\hline 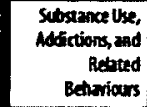 & C1.3 Warning signs, consequences & $\begin{array}{l}\text { C2.3 Mental health, gress } \\
\text { management (PS) }\end{array}$ & \\
\hline 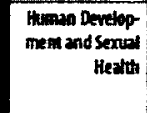 & 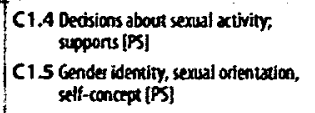 & $\begin{array}{l}\text { C2.4 Dection mating contraception } \\
{[15, \mathrm{CT}}\end{array}$ & C3 3 Redtionships and intimxy $[\mathrm{iS}, \mathrm{CT}$ \\
\hline
\end{tabular}




\section{Appendix B:}

\section{"Birds and Bees to be taught from Grade 3". Initial newspaper article from The Hamilton Spectator}

Birds and bees to be taught from Grade 3

The Hamilton Spectator

Thu Apr 152010

Page: Al

Section: Local

Byline: Carmelina Prete

Source: The Hamilton Spectator

Ontario elementary schoolchildren will learn more detailed sex education in earlier grades under a new province-wide curriculum that begins this September. The revised curriculum, to be taught in all school boards in Ontario, also means for the first time, children will learn about "invisible differences" such as sexual orientation and gender identity in Grade 3. In addition to learning about healthy relationships, self-esteem and the value of delaying sexual activity, students will learn about some potentially controversial issues. Some of the material to be discussed includes:

* In Grade 4: puberty and its physical and social changes. It's now taught in Grade 5.

* In Grade 5: the concept of personal desire, liking someone "in a special way."

* In Grade 6: personal pleasure in masturbation, vaginal lubrication and wet dreams.

* In Grade 7: sex acts such as oral sex and anal intercourse.

Some parents and educators don't support such explicit teachings about sexuality. "For some kids, it's too much too soon," said Vilia Milic, a Hamilton school-teacher who taught for 36 years before retiring last year. "We're not letting kids be kids. We're rushing them. Whatever innocence is left will no longer be there ... I don't think it's the responsibility of schools to go into specific detail. It's problematic." Chris Kovac, a Christian father of three, said teaching about same-sex relationships in Grade 3 is "completely inappropriate." "They're little kids. Why get them thinking about things that has no relevancy to them at this point?" he said. "I'm paying taxes into a system that's teaching my kids something that's counter to what we believe at home. They should have to remain neutral on matters of faith and religion. "

Ministry of Education spokes-person Gary Wheeler said teaching about gender identity and sexual orientation is part of the province's overall commitment to inclusive education. The province's equity and inclusive education strategy aims to see students of all diversities reflected in the curriculum. At the same time that the province implements these changes to the health curriculum, it is also expecting school boards to have equity policies in place that deal with issues of sexual orientation and gender identity. Those 
policies have also drawn strong reaction from upset parents who don't agree it should be incorporated into their children's education. The health and physical education curriculum, updated for the first time since 1998, reflects how the approach to teaching health has changed, said Wheeler. "The focus is on helping students build skills for making healthy choices."

Sarah Flicker, a York University assistant professor who reviewed the curriculum, says the ministry's commitment to acknowledge sexual pleasure and desires to youths is innovative and terrific. "Often when we talk to kids about sex-ed, it's a no-no-no, fingerwagging thing. It doesn't speak to the reality. Why do kids have sex? Because it feels good." So how does one determine what sex information is age appropriate? Physically, kids hit puberty sooner so it makes sense that it's taught in an earlier grade, she said. Psychologically, kids mature at different rates but the key is to provide the information before most kids get sexually active, she said. "If we wait until after they are sexually active, we are missing a key opportunity," she said. Lastly, one has to look at youth behaviour. Whether we like it or not, educators need to be pragmatic about what youth are actually doing, said Flicker. Hamilton's public board acknowledges some topics within sex-ed can be challenging to teach because of their personal nature and connection to family, religious or cultural values. Parents can choose to withdraw their children from those lessons. Hamilton's Catholic school board plans to teach curriculum in the context of their faith. Flicker said she's always hearing from youths about how awful sex-ed is. "I'm really hoping these curriculum shifts will change that discourse," she said.

cprete at thespec.com $905-526-2487$ 


\section{Appendix C:}

\section{Mr. McGuinty, Withdraw Sex Ed for 8 year-Olds Press Release by Charles McVety}

April 20, 2010

Toronto, ON

Monday, April 19, 2010

Leaders from various family focused groups with over 100,000 active members are calling for Premier Dalton McGuinty to withdraw the new Ontario Sex Education Curriculum, set to be implemented this September. The leaders are organizing Ontario parents to protest the new program by withdrawing their children from school on the Monday after Mother's Day, May 10th and joining a proposed rally in at 12:00 noon in Toronto. The location will be announced at www.StopCorruptingChildren.ca .

Dr. Charles McVety, President of Canada Christian College states that "it is unconscionable to teach , 8 year-old children same-sex marriage, sexual orientation and gender identity. It is even more absurd to subject 6 th graders to instruction on the pleasures of masturbation, vaginal lubrication and 12 year-olds to lessons on oral sex and anal intercourse. Mr. McGuinty plans to teach our children sexually explicit material that he did not give to his own. The Premier is not acting in trust. He must stop this form of corruption."

Brian Rushfeldt, Exec Director of Canada family Action said "Ontario's new sex education curriculum for 3 rd -7 th graders is bordering on criminal. Canada prosecutes persons for corrupting minors with explicit sex. To cause confusion in a young child's mind about being male or female is evil and teachers should refuse to present this onerous material."

Rev. Ekron Malcolm, Director of the Institute for Canadian Values states "I believe this is a form of controlling the minds and desires of our young children who should not have to think about sex at such a delicate age. This is just another form of exploitation through so-called "inclusive education."

Parents are asked to sign a petition at www.stopcorruptingchildren.ca

For interviews please call: Dr. Charles McVety 416-391-5000 ext 224

Mr. Brian Rushfeldt 403-295-2159

Rev. Ekron Malcolm 416-391-5000 ext 344 


\title{
Appendix D:
}

\section{Complete list of "Teacher Prompts" from 2010 Proposed Health and Physical Education Curriculum- Healthy Livings Strands, Grades 1-8.}

\author{
Grade 1 \\ Goal: identify body parts, including genitalia (e.g. penis, testicles, vagina, vulva), using correct \\ teminology [PS]
}

Teacher prompt: "We have talked about the body parts that everyone has. What body parts do only boys have and what body parts do only girls have?"

Student: "Boys have a penis. Girls have a vagina."

Teacher: "We talk about these body parts, like all body parts, with respect."

Goal: demonstrate an understanding of and apply proper hygienic procedures for protecting their own health and preventing the transmission of disease to others (e.g., washing hands with soap, using a tissue, sleeve sneezing, brushing and flossing teeth, not sharing hats or hairbrushes)

Teacher prompt: "Why is it important to wash your hands before you eat and after you use the washroom?"

Student: "Washing your hands helps to stop germs from spreading. We should wash with warm water and soap for as long as it takes to say the alphabet."

\section{Grade 2}

Goal: outline the basic stages of human development (e.g., infant, child, adolescent, adult, older adult) and related bodily changes, and identify factors that are important for healthy grow th and living throughout life

Teacher prompt: "How does your body change as you grow? What helps you to grow and be healthy?" Student: "As you grow, you get taller and bigger. Your bones grow. Your muscles grow. You grow faster at some stages than at others and not everyone grows the same amount at the same time. When you're an adult, your body doesn't grow anymore, but it still changes - for example, your skin gets more wrinkled and your hair might turn grey. Things that help make you healthy all through your life a re eating well, being active, getting enough sleep, and having people to care for you."

Teacher prompt: "When we look at growth and change throughout life, we can consider teachings from different cultures, including First Nation, Métis, and Inuit cultures, about the cycles of birth, life, and death. Different First Nations have different teachings and ceremonies for each life stage, and about growing and changes in roles and responsibilities at each stage. For example, the Anishinabe People teach about seven stages of life, and believe that at each stage, learning traditional teachings, such as the seven grandfather teachings, from family, community, and elders contributes to healthy growth and living."

Goal: demonstrate an understanding of and apply practices that contribute to the maintenance of good oral health (e.g., brushing, flossing, going to the dentist regularly for a checkup)

Teacher prompt: "How should you care for your teeth when you lose a tooth?"

Student: "I should make sure my hands are clean when I touch my teeth and remember to brush the gap between the teeth."

Teacher: "It is important to brush your teeth after eating, but if you can't, what else can you do?" Student: "I can rinse my mouth with water.

\section{Grade 3}

Goal: identify the characteristics of healthy relationships (e.g., accepting differences, being inclusive, communicating openly, listening, showing mutual respect and caring, being honest) and describe ways of overcoming challenges (e.g., bullying, exclusion, peer pressure, abuse) in a relationship

Teacher prompt: "Consider different types of relationships - with friends, siblings, parents, other 
adults - and think about the kinds of behaviour that help to make those relationships healthier. What can you do if you are having problems with a relationship?"

Student: "I can tell the person how I'm feeling, and we can try to work something out, or if we can't solve the problem, we can just say we disagree. We could also try to get advice from someone else."

Goal: identify factors (e.g., sleep, food, physical activity, heredity, environment, support from a caring adult, sense of belonging, peer influence) that affect physical development (e.g., of hair, skin, teeth, body size and shape) and or emotional development (e.g., of self-awareness, adaptive skills, social skills) [PS]

Teacher prompt: "There are factors that affect your development that you can control and other factors that you cannot control. Can you give me examples of both types of factors?"

Student: "I can't control my heredity, which affects my body size and shape. I can't control my family situation, or my cultural background, or where I grow up. I can usually control how often I brush my teeth, what foods I choose to eat from those that are available, how I choose my friends, and some of the activities I do."

Teacher: "Having a sense of belonging, of being accepted and understood, is important for emotional development. How can you show acceptance or understanding of stu-dents who may be different in some way - in shape and size, ability, background, family, or the way they do things - from others around them?"

Student: "I can stand up for someone who is being teased because they are different. I could try to learn more about people who do things differently than I do - such as learning about how some people who are deaf can talk using their hands, how some people with physical disabilities move with a wheelchair, or what someone who has a different religion from mine believes in."

\section{Grade 4}

Goal: describe the physical changes that occur in males and females at puberty (e.g., growth of body hair, breast development, changes in voice and body size, production of body odour, skin changes) and the emotional and social impacts that may result from these changes.

Teacher prompt: "During puberty, the male and female bodies undergo many changes. Everyone experiences these changes at different rates and at different times. Increases in weight and body fat are normal. Sometimes it is difficult getting used to the changes that are happening so quickly. Feelings can be much more intense. What are some of the feelings you might have as you start to experience changes with puberty?"

Student: "Excitement, happiness, embarrassment, confusion, and fear are some of the feelings I might have. It is sometimes hard to recognize what I am feeling and why things feel different."

Teacher prompt: "What can change socially as you start to develop physically?"

Student: "Relationships with friends can change, because sometimes people start being interested in different things at different times. Some people start 'liking' others. They want to be more than 'just friends' and become interested in going out. Sometimes people treat you as if you are older than you actually are because of how you look. Sometimes classmates, friends, or family make comments or tease you about the changes."

Teacher prompt: "Some cultures have traditions associated with puberty that mark the transition from childhood to adulthood. Can you give me some examples of these?"

Student: "In Judaism, a bar mitzvah or bat mitzvah is celebrated at age thirteen, when a boy or girl comes of age, according to religious law, and can now participate as an adult in the religious life of the community. Many Aboriginal societies have rites of passage that signal that adolescent boys and girls are ready to take on adult roles in society."

Goal: demonstrate an understanding of personal care needs and the application of personal hygienic practices associated with the onset of puberty (e.g., increased importance of regular bathing/ showering and regular clothing changes; use of hygiene products; continuing importance of regular hygiene practices, including hand washing, oral health care, and care of prosthetic devices and residual limbs).

Teacher prompt: "Why is it important to shower and change clothes more often as you approach puberty? What other things do you need to think about?"

Student: "As our bodies change, we perspire more. We should also be aware of spreading gems, and avoid sharing hats, lip gloss, hairbrushes, drinks, or towels." 


\section{Grade 5}

Goal: identify the parts of the reproductive system, and describe how the body changes during puberty

Teacher prompt: "Female body parts that mature and develop as a part of puberty include the vagina, cervix, uterus, fallopian tubes, ovaries, endometrium, and clitoris. Male body parts that mature and develop during puberty include the penis (with or without the foreskin), scrotum, urethra, testicles, prostate gland, seminal vesicles, and vas deferens. These changes occur as people become capable of reproduction. What are some physical changes that happen during puberty?"

Student: "During puberty, girls will develop breasts and get their periods for the first time. An increase in weight and body fat is nomal. Boys will becomemore muscular, get deeper voices, and grow facial and body hair. The penis and testicles will grow larger. Both boys and girls will grow hair under their arms, on their legs, and in their pubic area. The rate at which these changes occur will vary for each individual."

Goal: describe the processes of menstruation and spermatogenesis, and explain how these processes relate to reproduction.

Teacher prompt: "Menstruation is the medical term for having a 'period' and is the monthly flow of blood from the uterus. This begins at puberty. Not all girls begin menstruation at the same age.

Generally, every month, an egg leaves one of the ovaries and travels down one of the fallopian tubes towards the uterus. In preparation, the walls of the uterus develop a lining of extra blood and tissue to act as a cushion for the egg in case fertilization occurs. When an egg is fertilized, it attaches itself to the lining of the uterus and begins to develop into a baby. If fertilization does not occur, the lining of the uterus is no longer needed and is discharged through the vagina. This is the monthly flow of blood. The whole process is called the menstrual cycle. Can you summarize its purpose?"

Student: "It is how the female body gets ready for pregnancy."

Teacher: "The testicles are glands within the scrotum that produce sperm and hormones, beginning at puberty. After sperm develops in the testicles, it can travel through the epididymis until it reaches the vas deferens where it is stored until ejaculation occurs. During ejaculation, the prostate gland releases a liquid that mixes with the sperm from the vas deferens to make semen, which then leaves the body through the urethra. Fertilization can occur when the penis is in the vagina, sperm is ejaculated, and the sperm and egg connect. Babies can also be conceived by having the sperm and egg connect using assisted reproductive technologies. What is the purpose of sperm production?"

Student: "Sperm is needed for fertilization. When the sperm from the male and the egg from the female join together, pregnancy occurs."

Goal: describe emotional and interpersonal stresses related to puberty (e.g., questions about changing bodies and feelings, adjusting to changing relationships, crushes and more intense feelings, conflicts between personal desires and cultural teachings and practices), and identify strategies that they can apply to manage stress, build resilience, and enhance their mental health and emotional well-being (e.g., being active, writing feelings in a journal, accessing information about their concerns, taking action on a concern, talking to a trusted peer or adult, breathing deeply, seeking cultural advice from elders)

Teacher prompt: "Think about some things that could lead to stress for adolescents. For example, as they grow, people sometimes feel self-conscious about their bodies, but we all grow at different rates and you can't control how fast you grow. When you think about how to respond to stress, consider what is within your control and what is not."

Student: "Things I can control include whether I have a positive or negative attitude about things, how I show respect for myself and others, whether I ask for help when I need it, whether I am involved in activities at school and in my community, actions I take, whether I am open to new ideas, and whether I make my own decisions about things or let myself be influenced by others. Things I cannot control include where I was born, who is in my family, how much money my family has, and personal characteristics such as my skin colour, hair colour, whether I am male or female, my gender identity, sexual orientation, and overall body shape and structure. I could have a learning disability, a physical disability, or a health issue. All of these things are a part of who I am. I cannot control these things, but I can control what I do and how I act."

Teacher prompt: "It is normal to have stress and to have different feelings, including being happy, sad, angry, and excited at different times. Part of taking care of your mental health and emotional well-being is learning to be aware of and to monitor your own feelings. How do you know if you need help with your feelings?"

Student: "If you feel one way for a very long time - for example, if you always feel sad, anxious, or tired - that might be a sign that you need to get help to learn what is causing those feelings and what you can do about them." 
Teacher prompt: "As you enter adolescence, you may begin to develop new kinds of relationships and new feelings that you have not had before. Your relationships with your peers can becomemore stressful. Understanding how to respond to these new feelings and situations can reduce some of the stress that goes with them. For example, if you feel you 'like someone in a special way', what are some appropriate ways of sharing that information with someone else and what are ways that are inappropriate?"

Student: "You can show that you like someone by being extra nice to them, talking with them more, spending time with them, or telling them that you like them. Ways of showing that you like someone that are inappropriate include touching them without their permission, spreading rumours about them to others or online, or making fun of them in order to get attention."

\section{Grade 6}

Goal: identify factors that affect the development of a person's self-concept (e.g., environment, evaluations by significant others, stereotypes, awareness of strengths and needs, social competencies, cultural and gender identity, support, body image, mental health and emotional well-being, physical abilities)

Teacher prompt: "A person's self-concept and emotional health and well-being can be affected by a number of factors. Some of these are external factors - they come from outside ourselves. Others are internal factors - they come from within ourselves. Can you give me examples of external and internal factors that are protective - things that help a person develop a positive self-concept and improve their emotional well-being?"

Student: "Protective external factors include having support from family and caring adults, feeling that you have the right and are capable of taking steps to make things better, having clear boundaries, having high expectations of yourself, and being involved in activities that make you feel proud of what you've accomplished. Pro- tective internal factors include having a sense of purpose in life, having a good sense of identity or of who you are, having positive values, and having the skills you need to solve problems."

Goal: describe how they can build confidence and lay a foundation for healthy relationships by acquiring a clearer understanding of the physical, social, and emotional changes that occur during adolescence (e.g., physical: voice changes, skin changes, body growth; social: changing social relationships, increasing influence of peers; emotional: increased intensity of feelings, new interest in relationships with boys or girls, confusion and questions about changes)

Teacher prompt: "By getting questions answered and understanding that questions and changes are 'normal', adolescents will be better equipped to understand them-selves, relate to others, respond to challenges and changes in relationships, and build confidence. What are some questions that young people might have as changes happen during puberty and adolescence?"

Student: "Is how I am feeling nomal? Why is my body different from everybody else's? How do you tell someone you like them? Who can answer my questions about...?"

Teacher prompt: "Having erections, wet dreams, and vaginal lubrication are nomal things that happen as a result of physical changes with puberty. Exploring your body by touching or masturbating is something that many people will do and find pleas- urable. It is common and is not hamful and is one way of learning about your body."

Goal: make informed decisions that demonstrate respect for themselves and others and help to build healthier relationships, using a variety of living skills (e.g., personal and interpersonal skills; critical and creative thinking skills; following First Nation, Métis, and Inuit cultural teachings, such as medicine wheel teachings connected to the four colour or seven grandfather teachings, or other cultural teachings).

Teacher prompt: "In many ways, dating relationships can be similar to other relation- ships, such as those with friends or family. What are some of the signs of a healthy relationship, and what are some signs of potential trouble?"

Student: "In a healthy relationship, people show respect and care for each other. They try to communicate well and are honest with each other. Jealousy or behaviour that is too controlling can be signs of trouble."

Teacher: "How does knowing yourself help you to make good decisions when you are in a relationship?"

Student: "Being clear about your own values, priorities, strengths, and needs can help you sepa rate what is important to you from what is not. Knowing yourself well can help you see what you need to work on to make the relationship better." 
Teacher: "What communication skills can help you send information, receive infor-mation, and interpret information in an effective way in a relationship?"

Student: "Listening actively, interpreting body language, and negotiating are all important skills."

Teacher: "What social attitudes and behaviours are important in building a healthy relationship?"

Student: "It is important to have respect for others, show that you value differences, and be cooperative."

Teacher: "What should you consider when making any decision regarding a relationship?"

Student: "My comfort level, my personal and family values, and my personal limits are some of the things I should consider."

Teacher: "Changing or ending relationships can be difficult. What are some ways to deal positively with changing or ending relationships?"

Student: "Talk about how you feel with someone you trust. Think about what you can learn from the situation that you can apply in the future. Remember that although the hurt feelings can be very intense at the beginning, you will start feeling a little better over time. If you are the one ending the relationship, treat the other person with respect and consider how they may be feeling. Try to explain how you feel. Ending a relation- ship over the phone or online may not be a sensitive approach."

\section{Grade 7}

Goal: explain the importance of having a common understanding with a partner about delaying sexual activity until one is older (e.g., choosing to abstain from any genital contact; choosing to abstain from having vaginal or anal intercourse; choosing to abstain from having oral-genital contact), the reasons for not engaging in sexual activity, and the need to communicate clearly with each other when making decisions about sexual activity in the relationship

Teacher prompt: "The term abstinence can mean different things to different people. People can also have different understandings of what is meant by having or not having sex. Be clear in your own mind about what you are comfortable or uncomfortable with. Being able to talk about this with a partner is an important part of sexual health. Having sex can be an enjoyable experience and can be an important part of a close relationship when you are older. But having sex has risks too, including physical risks like sexually transmitted infections - which are common and which can hurt you - and getting pregnant when you don't want to. What are some of the emotional considerations to think about?"

Student: "It's best to wait until you are older to have sex because you need to be emotionally ready, which includes being able to talk with your partner about how you feel, being prepared to talk about and use protection against STIs or pregnancy, and being prepared to handle the emotional ups and downs of a relationship, including the ending of a relationship, which can hurt a lot. Personal values, family values, and religious beliess can influence how you think about sexuality and sexual activity. A person should not have sex if their partner is not ready, if they are feeling pressured, if they are unsure, or if they are under the influence of drugs or alcohol."

Goal: identify common sexually transmitted infections (STIs), and describe their symptoms

Teacher prompt: "Common sexually transmitted infections include human papillo-mavirus (HPV), herpes, chlamydia, gonorrhea, and hepatitis B. Some have visible symptoms but most do not, so it's hard to tell if you or someone else has an STI. All STIs can have a significant impact on your health. What are some symptoms of an STI? If an STI has no symptoms, how can you find out if you have it?"

Student: "You can see some STIs, such as pubic lice or genital warts, and other STIs have symptoms such as redness or pain while urinating. Even if you don't see or experience any symptoms, you should get tested by a doctor if you think you might have been exposed to an STI. Depending on the STI, tests can be done by taking swabs from the cervix, vagina, or urethra or by taking urine or blood samples." identify ways of preventing STIs, including HIV, and/ or unintended pregnancy, such as delaying first intercourse and other sexual activities until a person is older and using condoms consistently if and when a person becomes sexually active

Teacher prompt: "Engaging in sexual activities like oral sex, vaginal intercourse, and anal intercourse means that you can be infected with an STI. If you do not have sex, you do not need to worry about getting an STI. (By the way, statistics show that young people who delay first intercourse are more likely to use protection when they choose to be sexually active.) If a person is thinking of having sex, what can they do to protect themselves?"

Student: "They should go to a health clinic or see a nurse or doctor who can provide important information about protection. People who think they will be having sex sometime soon should keep a condom with them so they will have it when they need it. They should also talk with their partner about using a condom before they have sex, so both partners will know a condom will be used. If a partner says they do not want to use a condom, a person should say, 'I will not have sex without a condom.' If you do have sex, it is important that you use a condom every time, because condoms help to protect you 
against STIs, including HIV, and pregnancy."

Teacher prompt: "HIV (Human Immunodeficiency Virus) is the virus that leads to AIDS (Acquired Immune Deficiency Syndrome). HIV is a serious, incurable infection. HIV attacks the cells in the body that help to fight infections until they are no longer able to do their job. With treatment, the damage that HIV does to the body's immune system can be slowed or prevented. But HIV infection cannot be cured. The only way to know if you have HIV is to get an HIV test. A person develops AIDS when their immune system has been weakened by HIV and they can no longer fight other infections. It is common for a person with AIDS to develop other infections, such as pneumonia or some kinds of cancer. HIV can be transmitted whether or not someone has symptams of the infection. HIV transmission results from specific activities and does not occur through everyday contact with someone living with HIV / AIDS. Sexual activity is not the only way a person can get HIV/ AIDS. What are some of the other ways a person can be infected with HIV, and what can be done to prevent the spread of HIV / AIDS?"

Student: "HIV is transmitted through contact with bodily fluids - semen, blood, vaginal fluid, and breast milk. HIV cannot live outside the body. For you to be infected, the virus must enter your bloodstream. That can happen through the use of needles as well as through sexual activity. To prevent the spread of HIV / AIDS, avoid high-risk behaviours like vaginal intercourse, anal intercourse without a condom, and injection drug use. It is very important that you use a condom if you do have sex. Avoid sharing needles or using needles that have not been sterilized for any purpose, including piercing, tattooing, or injecting steroids."

Goal: demonstrate an understanding of physical, emotional, social, and psychological factors that need to be considered when making decisions related to sexual health (e.g., sexually transmitted infections [STIs], possible contraceptive side effects, pregnancy, protective value of vaccinations, social labelling, gender identity, sexual orientation, self-concept issues, relationships, desire, pleasure, cultural teachings).

Teacher prompt: "Thinking about your sexual health is complicated. It's important to have a good understanding of yourself before getting involved with someone else. It's not just about making a decision to have sex or waiting until you are older. It's also about things such as your physical readiness; safer sex and avoiding consequences such as pregnancy or STIs; your sexual orientation and gender identity; your under- standing of your own body, including what gives you pleasure; and the emotional implications of sexual intimacy and being in a relationship. It can include religious beliefs. It includes moral and ethical considerations as well, and also involves the need to respect the rights of other people. Can you explain what is meant by a moral consideration?"

Student: "A moral consideration is what you believe is right or wrong. It is influenced by your personal, family, and religious values. Every person in our society should treat other people fairly and with respect. It is important to take this into account when we think about our relationships, sexual behaviour, and activities."

Teacher: "Like any other decision, a decision about sexual health requires you to look at all sides of an issue. How can you do that?"

Student: "You need to consider the pros and cons of any decision you are making, and how those decisions will affect both you and others."

\section{Grade 8}

Goal: identify and explain factors that can affect an individual's decisions about sexual activity (e.g., previous thinking about reasons to wait, including making a choice to delay sexual activity and establishing personal limits; perceived personal readiness; peer pressure; desire; curiosity; selfconcept; awareness and acceptance of gender identity and sexual orientation; legal concerns; awareness of health risks, including risk of STIs and blood-borne infections; concerns about risk of pregnancy; use of alcohol or drugs; personal or family values; religious beliefs; cultural teachings; access to information; media messages), and identify sources of support regarding sexual health (e.g., a health professional [doctor, nurse, public health practitioner], a community elder, a teacher, a religious leader, a parent or other trusted adult, a reputable website)

Teacher prompt: "How would thinking about your personal limits and making a personal plan influence decisions you may choose to make about sexual activity?"

Student: "Thinking in advance about what I value and what my personal limits are would help me to respond and make decisions that I felt comfortable with in differ-ent situations. I would be able to approach a situation with more confidence and stick to what I had planned. I would be less likely to be caught off guard and have to react without having thought through the options and possible consequences."

Teacher prompt: "Why is it important to get information from a credible source before making a decision about being sexually active?"

Student: "Having more information - and information that you can trust - helps you make better decisions for yourself. Taking time to get more information also gives you more time to think. Teens who 
consult a health professional before being sexually active are more likely to use protection, such as condoms, if they choose to be sexually active."

Goal: demonstrate an understanding of gender identity (e.g., male, female, two-spirited, transgendered, transsexual, intersex) and sexual orientation (e.g., heterosexual, gay, lesbian, bisexual), and identify factors that can help individuals of all identities and orientations develop a positive selfconcept.

Teacher prompt: "Gender identity refers to a person's internal sense or feeling of being male or female, which may or may not be the same thing as one's biological sex. It is different from and does not determine a person's sexual orientation. Sexual orientation refers to a person's sense of affection and sexual attraction for people of the same sex, the opposite sex, or both sexes. Gender identity and sexual orientation are connected to the way we see ourselves and to our interactions with others.

Understanding and accepting our gender identity and our sexual orientation can have a strong impact positive or negative - on the development of our self-concept. A person's self-concept can develop positively if the person understands and accepts his or her gender identity and sexual orientation and is accepted by family and community. It is harder to develop a positive self-concept, however, if the way a person feels or identifies does not meet perceived or real societal noms and expectations or is not what they want, or if they do not feel supported by their family, friends, school, or community. A person's self-concept can be hamed if a person is questioning his or her gender identity or sexual orientation and does not have support in dealing with his or her uncertainties. What kind of support do people need to help them under- stand and accept their gender identity and sexual orientation?"

Student: "Having role models that you can relate to - for example, people of similar ages or cultures - is important. So is having all gender identities and sexual orientations portrayed positively in the media, in literature, and in materials we use at school. Family, school, and community support are crucial. Additional help can come from trusted adults, community organizations, and school support systems such as gay- straight alliances."

Goal: develop their understanding about sexual health (e.g., about issues such as abstinence; the choice to delay first intercourse; setting sexual limits; safer sex and pleasure; use of contraception, including condoms, for pregnancy and STI prevention), using knowledge of self and of safe-sex practices and contraception (including condom use), seeking additional information and support as needed, and practising (e.g., through role play) the communication, assertiveness, and refusal skills that may be needed for decision making in real-life contexts.

Teacher prompt: "What do teenagers need to know about contraception and safer sex in order to protect their sexual health and set appropriate personal limits?"

Student: "Teenagers need to know about the benefits and risks of different types of contraception. They need to understand that the only $100 \%$ sure way of not becoming pregnant or getting an STI, including HIV, is not having sexual contact. Those who choose to be sexually active also need to know which contraceptive methods provide a protective barrier against disease as well as pregnancy. Condoms provide protection against both pregnancy and STIs - but to be effective, they need to be used properly and used every time. Teenagers need to understand how important it is to talk with their partners about sexual health choices and about keeping safe. They have to develop the skills to communicate their thoughts effectively in these conversations. This takes practice." 


\section{References}

Abrams, M. 1959. The Teenage Consumer. London: London Press Exchange.

Adams, M. 1997. The Trouble with Normal. Toronto: University of Toronto Press.

Alter, J. 1999. "The New Powers that Be." Newsweek, January 18, pg 24-35.

American Psychological Association, 2010. Report of the APA Task Force on the Sexualization of Girls. Retrieved on August 24, 2010 from http://www.apa.org/pi/women/programs/girls/report-full.pdf

Angelides S. 2003. "Historicizing Affect, Psychoanalyzing History: Pedophilia and the Discourse of Child Sexuality." Journal of Homosexuality 46:79-109.

Apel, Y. 2010. "Sex ed: Stop corrupting our kids". The Hamilton Spectator, April 23, p. A14. (Retrieved from Lexis/Nexis on May 29, 2012).

Babbage, M. 2010. "Ontario may start sex ed in Grade 1: Protest". The Daily Gleaner, April 21, p. A7. (Retrieved from Lexis/Nexis on May 29, 2012).

Bailey, M. 1999. "Homosexuality and Mental Illness." Archives of General Psychiatry $56(10): 883-884$.

Barker, C. 2005. Cultural Studies: Theory and Practice. London: Sage.

Bauer, G. 2004. "Pride and Joy." Today's Parent 21(8):130-135

Bay-Cheng, L. 2010. "The Trouble of Teen Sex: The construction of adolescent sexuality through school based sexuality education." Sex Education 3:61-74.

Bendroth, M.L. 1993. Fundamentalism and Gender, 1875 to the Present. Yale University Press.

Benninga, J.S. 1991. Moral character and civic education in the elementary school. New York: Teachers College Press.

Benzie, R. 2010. "Analysis: Dalton McGuinty's sex-ed surrender motivated by politics". The Toronto Star, April 23 $3^{\text {rd }}$. (Retrieved from Factivia on August 13, 2012).

Benzie, R. and Rushowy, K. 2010. "Changes to sex-ed curriculum raise ire of family groups". The Toronto Star, April 20. (Retrieved from Factivia on May 29, 2012).

Beauvoir, S. 1989. The second sex (original 1972). Translated by H.M Parshley. Penguin Books. 
Blackwell, E. 1884." Counsel to Parents on the Moral Education of their Children in Relation to Sex" in Danielle Egan and Gail Hawkes (Eds). Producing the Prurient through the Pedagogy of Purity: Childhood Sexuality and the Social Purity Movement. 1-16.

Bottomore, S. 1999. "The Panicking Audience?: Early Cinema and the 'Train Effect'." Historical Journal of Film, Radio and Television 19(2):177-216.

Bruner, S. 2003. Don't Do That: The Regulation of Youth Sexuality in the Canadian Print Media. Masters Thesis, Graduate School of Journalism. University of British Columbia.

Bullough, V. 2004." Age of Consent: A Historical Overview" in H Graupner and V. Bullough (Eds) Adolescent Sexuality and the Criminal Law. New York: Hawthorne Press. 25-42.

Burgett, B. 2008. "Sex, Panic, Nation." American History Advance Access 21:1-19.

Burns, R. and Crawford, C. 1999. "School shootings, the media and public fear: Ingredients for a moral panic." Crime, Law \& Social Change 32:147-168.

Cantril, H. 1966. The Invasion from Mars: A study in the Psychology of Panic. New York: Harper Tourchbooks.

Clarke, J., Hall, S., Jefferson, T. and Roberts, B. 1976. "Subcultures, cultures and class" in Hall, S. and Jefferson, T. (Eds.), Resistance Through Rituals: Youth Subcultures in Post-War Britain. Routledge: New York. 9-66.

Cohen, S. 1972. Folk Devils and Moral Panics: The Creation of the Mods and Rockers. London: MacGibbon \& Keef.

Cohen, S. and Young, J. 1973. The Manufacture of News: Social problems, Deviance and the Mass Media (Community and Society). London: Constable Publishing.

Craine, D. 2010 "Mandatory Curriculum for Ontario Schools Promotes Homosexuality, Masturbation". Lifesitenews. Retrieved June 7, 2012 from http://www.lifesitenews.com/news/archive/ldn/2010/mar/10030216

Critcher, C. 2002. "Media, Government and Moral Panic: the Politics of Paedophilia in Britain 2000-1." Journalism Studies 3(4):521-535.

Critcher, C. 2006. Critical Readings: Moral Panics and the Media. London: Open University Press. 
D'Amato, L. 2010. 'New sex-education curriculum worries Cambridge mom and school trustees". The Cambridge Reporter, April 22, p. 01. (Retrieved from Lexis/Nexis on May 28, 2012).

Dauda, C. 2010. Sex, Gender and Generation: Age of Consent and Moral Regulation in Canada." Politics \& Policy 38(6):1159-1185.

DeRoche, E.F. and Williams, M. 1998. Educating hearts and minds: A comprehensive character education framework. Thousand Oaks California: Corwin Press.

DiManno, Rosie. 2010. "Sex ed taught Dalton McGuinty a lot about role reversal". The Toronto Star, April 23. (Retrieved from Factivia on August 13, 2012).

Dollimore. 1991. Sexual Dissidence: Augustine to Wilde, Freud to Foucault. Claredon Press: Oxford.

Donovan, C. 2000. "On Diversity" in A. Sonnie (Ed.), Revolutionary voices: A multicultural queer youth anthology. Los Angeles: Alyson Books. 205-206.

Douglas, M. and Wildavsky, A. 1982. Risk and Culture: As Essay on the Selection of Technological and Environmental dangers. Berkeley: University of California Press.

Dowler, K. 2006. "Sex, lies and videotape: The presentation of sex crime in local television news." Journal of Criminal Justice 34(4):383-392.

Dunn, M. 2010. "It's too bad! McGuinty shelves sex-ed changes" The Ottawa Citizen April 23, A11. (Retrieved from Lexis/Nexis on May 29, 2012).

Durham, G. 2008. The Lolita Effect: Media sexualization of girls and what we can do about it. Woodstock and New York: Peter Mayer Publishers Inc.

Durkheim, E. 1964. The Division of Labour in Society. Cambridge: The Free Press.

Edelman, M. 1988. Constructing the political spectacle. Chicago: University of Chicago.

Egan, D. and Hawkes, G. 2008. "Landscapes of Erotophobia: The Sexualized Child in the Postmodern Anglophone West." Sexuality and Culture 12:193-203.

Egan, D. and Hawkes, G. 2009. "Childhood Sexuality, Normalization and the Social Hygiene Movement in the Anglophone West, 1900-1935". Social History of Medicine 23:56-78.

Elder, G. 1975. "Adolescence in the Life Cycle" In Dragastin, S. and Elder, G. (eds), Adolescence in the Life Cycle, Psychological Change and Social Context. Washington: Hemisphere/Halsted Publishing. 
Erickson, K.T. 1966. Wayward Puritans: A Study of the Sociology of Deviance. New York: John Wiley.

Foucault, M. 1972. The Archaeology of Knowledge and the Discourse on Language. New York: Pantheon Books.

Foucault. M. 1978. The History of Sexuality (Volume 1). New York: Vintage Books.

Frost, J. and Darroch-Forest, J. 1995. "Understanding the impact of effective teenage pregnancy prevention." Family Planning Perspectives 27(5):188-195.

Glassman, J. 1998. “. . . Or a Made-Up Menace?”. The Washington Post, May 26, p. A17.

Goffman, E. 1974. Frame Analysis: An essay on the organization of experience. New York: Harper and Row.

Goode and Ben-Yehuda. 1994. Moral Panics. USA: Blackwell Publishers.

Gordon, A. 2010. "Why sex-ed should stay in schools". The Toronto Star, April29. (Retrieved from Lexis/Nexis on August 20, 2012) .

Graff, H. 1995. Conflicting Paths: Growing Up in America. United States of America: Library of Congress Cataloguing In Publication Data.

Greenberg, L. 2010. "McGuinty vows to implement most of controversial health curriculum into Ontario schools". CanWest News Service, April 27. (Retrieved from Lexis/Nexis on May 29, 2012).

Halbertam. 1999. Female Masculinities. Durham: Duke University Press.

Hall, G. S. 1904. Adolescence: Its Psychology and Its Relations to Physiology, Anthropology, Sex, Crime, Religion, and Education. New York: Appleton.

Hall, S. 1996. "The Problem of Ideology: Marxism without Guarantees" in Morley, D. and Hsing-Chen, K. (Ed.), Start Hall: Critical Dialogues in Cultural Studies. 2546.

Hamel, R. 2010. "Sex education in Ontario: A clash of worldviews". The Guelph Mercury, May 7, pp. 01. (Retrieved from Lexis/Nexis on May 29, 2012).

Hammer, K. and Howlett, K. 2010. "The End of Innuendo: Ont. Schools Making Sex Education More Explicit". The Globe and Mail, April 21, p. A1. (Retrieved from Lexis Nexis on May 28, 2012). 
Hamilton Community News, 2010. Anonymous Contributor, "Sex-Ed Surrender" Editorial, Apil 29. (Retrieved from Lexis/Nexis on May 29, 2012).

Hamilton Spectactor, 2010. Anonymous Contributor "Love, sex and everything inbetween; New provincial curriculum means elementary students will begin learning about matters such as sexual orientation as early as Grade 3. Do you support these changes?" Opinions Section, April 17.

(Retrieved from Lexis/Nexis on May 29, 2012)

Hawley, J. 1994. Fundamentalism and Gender. Oxford University Press.

Hofstadter, R. 1963. The paranoid style of American politics: And other essays. Cambridge: Harvard University Press.

Howland, C. 1999. Religious Fundamentalisms and the Human Rights of Women. New York: St. Martin's Press.

Hebdige, D. 1988. Hiding in the Light: On Images and Things. London: Routledge.

Herdt, G. 2009. Moral Panics, Sex Panics: Fear and the fight over sexual rights. New York: New York University Press.

Hier, S. 2002. "Conceptualizing Moral Panic through a Moral Economy of Harm." Critical Sociology 28(3):311-334.

Humphrey, A. 2010. “Ontario's sex-ed battlefield: Saving lives or encouraging early sex?". The National Post, April 23. (Retrieved from Lexis/Nexis on May 28, 2012).

Irving, J. 2005. "Anti-Gay Politics Online: A Study of Sexuality and Stigma on National Websites." Sexuality Research and Social Policy 2:3-22.

Jackson, S. and Scott, S. 1999. "Risk Anxiety and the Social Construction of Childhood" in D. Lupton (Ed.) Risk and Sociocultural Theory, New Directions and Perspectives. United Kingdom: Cambridge University Press. 86-107.

Jackson, S. and Scott, S. 2004. "Sexual Antinomoies in Late Modernity". Sexualities 7(2):233-248.

James, A., Jenks, C., and Prout, A. 1998. Theorizing Childhood. Cambridge: Blackwell Publishers.

James, A. and James, A. eds. 1990.Constructing Childhood Theory, Policy and Social Practise. New York: Palgrave Macmillan. 
Javat, T. 2010. "Parenting: What you need to know about: Sex education in school". Canadian Newcomer, Retrieved on August 13, 2012 from http://www.cnmag.ca/issue-25/586-parenting-what-you-need-to-know-about-sexeducation-at-school-e00

Jenkins, P. 1998. Moral Panic: Changing Conceptions of the Child Molester in Modern America. New Haven: Yale University Press.

Jewkes, Y. 2004. Media and Crime. London: Sage Publications.

Jhally, S. 1999. Tough Guise: Abridged Version, Violence, Media, and the Crisis in Masculinity [Videotape]. St. Northampton: Media Education Foundation.

Kettle, N. 2010. “Politicians aren't Sex-Educators". Inside Hamilton, April 28. (Retrieved from Lexis/Nexis on July 23, 2012).

Kincaid, J.R. 1998. Erotic Innocence: The culture of child molesting. Durham and London: Duke University Press.

Kinsman, G. 1994. The Regulation of Desire: Homo and Hetero Sexualities (2nd Ed.) Montreal: Black Rose Books.

Kirby, Douglas, Laris, B.A and Rolleri, Lori. 2006. "Sex and HIV Education Programs: Their Impact on Sexual Behaviors of Young People Throughout the World." Journal of Adolescent Health 40(3):206-217.

Kirby, D. 1992. "School-based programs to reduce sexual risk behaviors. A review of effectiveness." Public Heath Reports 109(3):339-360.

Kraft-Ebing. R. 1928 (original 1886). Psychopathis Sexualis with Especial Reference to the Antipathic Sexual Instinct: A Medico-Forensic Study, Revised Edition. Philadelphia: Physicians and Surgeons.

Kunkel, D., Cope-Farrar, K.M., Biely, E., Farinola, W.J. \& Donnerstein, E. 2001. Sex on TV: II A biennial report to the Kaiser Family Foundation. Menlo Park, CA: Kaiser Family Foundation.

Lee, N. 2001. Childhood and Society Growing Up in an Age of Uncertainty. Philadelphia, PA and Birmingham, UK: Open University Press.

Lehr, V. 2008. "Developing Sexual Agency: Rethinking Late Nineteenth and Early Twentieth Century Theories for the Twenty-First Century." Sexuality and Culture 12:204-220.

Lesko, N. 2001. Act Your Age: The Cultural Construction of Adolescence. New York and London: Routledge. 
Marty, M. and Appleby, S. 1993. Fundamentalisms and Society: Reclaiming the Sciences, the Family and Education, Vol 2. Chicago: University of Chicago Press.

Mauldon, J. and Luker, K. 1996. "The effects of contraception education on method use at first intercourse." Family Planning Perspectives 28:19-24.

McGarvie, S. 2010. "Kids need the facts on sex". The Ottawa Citizen, Citizen Special. April 29. (Retrieved from Lexis/Nexis on May 28, 2012).

McKay, A. 1998. Sexual Ideology and Schooling: Towards Democratic Sexuality Education. London: Althouse Press.

McRobbie, A. and Thornton, S. 1995. "Rethinking 'moral panic' for multimediated social worlds." British Journal of Sociology 46(4):559-574.

McWhorter, L. 1999. Bodies and pleasures: Foucault and the politics of Sexual Normalization. Indiana: Indiana University Press.

McVety, C. 2010. "Mr. McGuity, Withdraw Sex ed for 8 year-olds". Institute for Canadian Values. Retrieved June 21, 2012 from http://www.canadianvalues.ca/kmitan/377mr mcguinty withdraw sex ed for 8 year_olds.php

Ministry of Education. 2010a. Health and Physical Education Curriculum, Grades 1-8. Revised Edition. Retrieved, August 13, 2012 from http://www.edu.gov.on.ca/eng/teachers/curriculum.html

Ministry of Education. 2010b. Health and Physical Education Curriculum, Grades 1-8, Interim Edition. Retrieved August 13, 2012, from http://www.edu.gov.on.ca/eng/teachers/curriculum.html

Ministry of Education, 1998. Health and Physical Education Curriculum, Grades 1-8. Retrieved August 13, 2012 from http://www.edu.gov.on.ca/eng/teachers/curriculum.html

Minwalla, O., Rosser, B.R., Feldman, J. and Varga, C. 2005. "Identity Experience Among Progressive Gay Muslims in North America". Culture, Health and Sexuality 2:113-128.

Moran, J.P. 2000. Teaching Sex: The shaping of adolescence in the $20^{\text {th }}$ century. Cambridge: Harvard University Press.

Morris, R.W. 1994. Values in sexuality education: a philosophical study. Lanham: University Press of America. 
Nguyen, L. 2010. "Ontario Premier Defends Sex-Ed Curriculum". CanWest News Service Toronto, April 20. (Retrieved from Lexis/Nexis on May 28, 2012).

Nolte, J. 1984." Sex education in Canadian classrooms". Tellus Planned Parenthood Federation of Canada Newsletter. September, 13-15.

Norris, P. 2000. A Virtuous Circle: Political Communications in Post-Industrial Societies. New York: Cambridge University Press.

Oneschuk, B. 2010. "Sex Education not a 'diamond idea". The Windsor Star, May 7, p. A7. (Retrieved from Lexis/Nexis May 28, 2012).

Park, R. 1923. "The Natural History Of The Newspaper" The American Journal of Sociology 29(3):273-289.

Pearce, J. 2010. "Re: Sex education of Grade 3 primary students". The Windsor Star, April 27, p. A7. (Retrieved from Lexis/Nexis on May 28, 2012).

Philo, G. 1996. Media and Mental Distress. New York: Longman.

Plummer, K. 1975. Sexual Stigma: An Interactionist Account. London: Routledge and Kegan Paul.

Plummer, K. 1997. Telling Sexual Stories: Power, Change and the Social World, London: Routledge.

Postman, N. 1982. The Disappearance of Childhood. New York: Random house.

Prete, C. 2010. "Birds and bees to be taught from Grade 3". The Hamilton Spectator, April 15, p. A1 (Retrieved from Lexis Nexis on August 22, 2012).

Provenzo, E.F. 1990. Religious Fundamentalism and American Education: The battle for the public schools. Albany: State University of New York Press.

Qvortrup, J., ed. 2005. Studies in Modern Childhood: Society, Agency, Culture. Houndsmill, UK and New York: Palgrave Macmillan.

Randall, D. 2010. "The real lesions behind sex education; Turns out certain religious elements still play a big role in Ontario schools". The Ottawa Citizen, April 24, C.1. (Retrieved from Lexis/Nexis on June 2, 2012).

Rayside, D. 2010. "Sex Ed in Ontario: Religious Mobilization and the Socio-Cultural Anxiety". Paper presented at the Annual Meeting of the Canadian Political Science Association, Concordia University, Montreal, June 2010.

Riesebrodt, M. 1993. Pious Passion: the emergence of modern fundamentalism in Iran and the United States. Berkely: University of California Press. 
Roberts, D. 2000. "Media and youth: access, exposure and privatization." Journal of Adolescent Health 27(2):8-14.

Robinson, K. 2005. "Childhood and Sexuality: Adult Constructions and Silenced Children". In J. Mason, J Mason \& T Fattore (Eds.), Children taken seriously: Theory, practise and policy. London: Jessica Kingsley Publishers. 66-78.

Robson, J. 2010. "Classroom Engineering". The Ottawa Citizen, May 7, pp. A12. (Retrieved from Lexis/Nexis on June 7, 2012).

Romesburg, D. 2008. "Tightrope of Normalcy." Journal of Historical Sociology 21:417442.

Rogers, N. 2010. "View from here- No sex ed please, we're Canadian". The Times Educational Supplement, May 28, pp.8, No 2165. (Retrieved from Lexis Nexis on May 9, 2012).

Rubin, G. 1985. "Thinking Sex: Notes for a Radical Theory of the Politics of Sexuality" in Carol S. Vance (ed.) Pleasure and Danger, Harper Collins Canada. 149-165.

Rujeedawa, R. 2010. “McGuinty's Sex-Ed Surrender". Hamilton Community, April 29, pp. A01. (Retrieved from Lexis/Nexis on July 23, 2012).

Shapiro, J. 1993. "Teenage Sex: Just Say 'Wait". US News and World Report, July 18, Volume 115, No. 4.

Shaw, D., McLeod, J. and Yoon, S.H. 2001. "Communication, Context and Community. An Exploration of Print, Broadcast and Internet Influences". Communication Research 28(4):464-506.

Skaggs, C. 1996. With God on our side: The rise of the religious right in America. Lumiere Productions, Inc.

Smith, A. 2010. "Better Sex Education Still Needed". The Guelph Mercury, April 23, pp. 01. (Retrieved from Lexis/Nexis on May 29, 2012).

Sparks, C. and Tulloch, J (eds.). 2000. Tabloid Tales: Global Debates Over Media Standards. Maryland: Rowman \& Littlefield Publishers, Inc.

Statistics Canada. 2009. "Police Reported Crime Statistics in Canada, 2009". Retrieved August 15, 2012 from http://www.statcan.gc.ca/pub/85-002-x/2010002/article/1 1292-eng.htm

Surette, R. 1992, Media, Crime, and Criminal Justice: Images and Realities. Pacific Grove: Brooks/Cole. 
Sutherland, K. 2003 "From Jailbird to Jailbait: Age of Consent Laws and the Construction of Teenage Sexualities." William and Mary Journal of Women and the Law $9(3): 313-349$.

Taylor, L. and Willis, A. 1999. Media Studies: Texts, Institutions and Audiences. Oxford, UK: Blackwell Publishers.

Thompson, K. 1998. Moral Panics. London: Routledge

Thompson, Scott. 2010. "What are kids being taught about sex?" The Hamilton Spectator, May 4, pp. A15. (Retrieved from Lexis/Nexis on May 29, 2012).

Tuchman, G. 1978. Making News. New York: The Free Press.

Vergari, S. 2000. "Morality Politics and Educational Policy: The Abstinence-Only Sex Education Grant." Educational Policy 14:290-312.

Walkerdine, V. 1998 "Popular Culture and the Eroticization of Little Girls", in K. Jenkins (ed.) A Children's Culture Reader. Cambridge: Harvard University Press. 254265.

Walsh, K. 2004. "The Sexual Rights of Children and the Age of Consent." Paper presented at the $2^{\text {nd }}$ Global Conference on Good Sex, Bad Sex: Sex Law, Crime and Ethics, May $3^{\text {rd }}, 2010$, Prague, Czech Republic.

Waschuk, Mary Ellen. 2010. "Love, Sex and Everything In-Between." The Hamilton Spectator. April 17, pp. WR07. (Retrieved from Lexis/Nexis on July 23, 2012).

Williams, L. 2004. Porn Studies. New York: Duke University Press.

Weeks, J. 1986. Sexuality ( $2^{\text {nd }}$ Ed.). London: Routledge Publications.

Weeks, J. 1998. "The Sexual Citizen." Theory, Culture \& Society 15(3):35-52

Welch, M., Price, M. and Yankey, N. 2002. "Moral Panic Over Youth Violence: Wilding and the Manufacture of Menace in the Media." Youth and Society 34(1):3-30.

Wong, J. (2006). "Age of consent to sexual activity in Canada: Background to proposed new legislation on 'age of protection'." Canadian Journal of Human Sexuality 15(3/4):163-169.

Wyatt, G.E and Riederle. 1994. "Reconceptualizing issues that affect women's sexual decision making and sexual functioning." Psychology of Women Quarterly 18(4):611-625.

Wynne, E. and Ryan, K. 1993. Reclaiming our schools. New York: Macmillan. 
Young, J. 1971. "The Role of the Police as Amplifiers of Deviance" in Cohen, S. (ed.), Images of Deviance. Harmondsworth: Penguin.

Zabin, M. and Hayward, S. 1993. Adolescent Sexual Behavior and Childbearing. Newbury Park: Sage Publications.

Zelizer, B. 2000. "Foreword." Pp. ix-xv in Tabloid Tales: Global Debates Over Media Standards, by Sparks, C. and Tulloch, J. (eds). Maryland: Rowman \& Littlefield Publishers, Inc. 